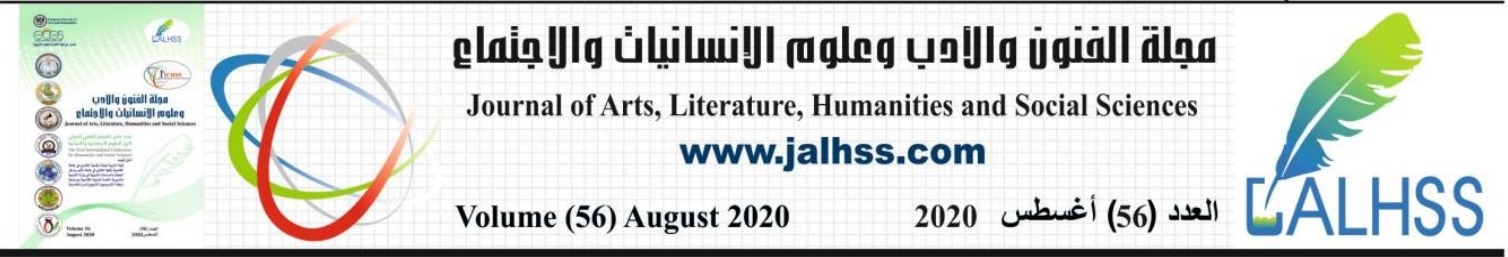

\title{
تمكين المرأة ... الفرص والتحديات
}

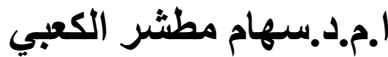

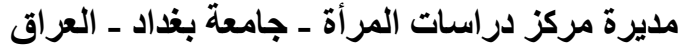

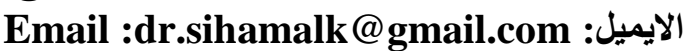 \\ Siham.mtashar@wsc.uobaghdad.edu.iq
}

اصبح موضوع تمكين المر أة في القرن الحادي و العشرين قضية ساخنة حول العالم ؛ فالمر اة الحديثة تبحث عن

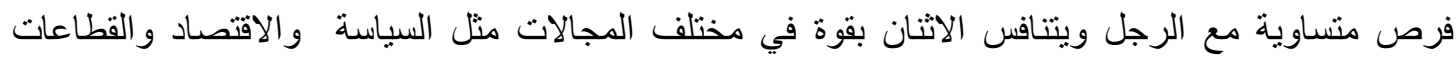

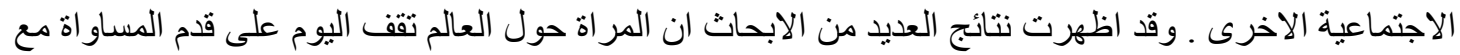

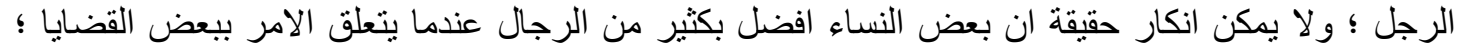

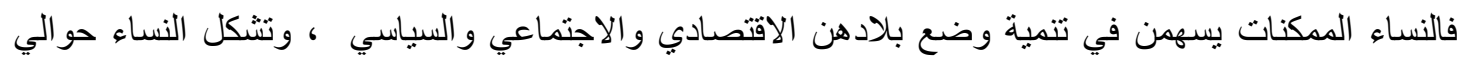

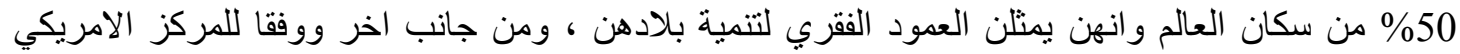

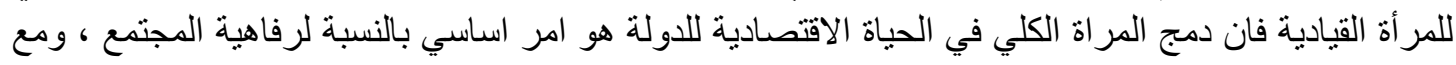

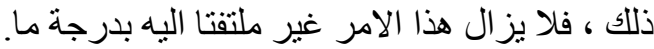

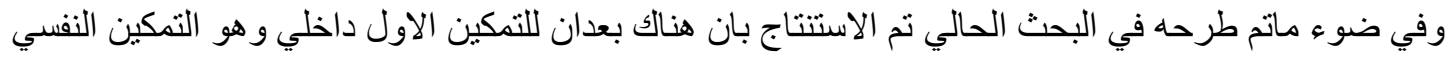

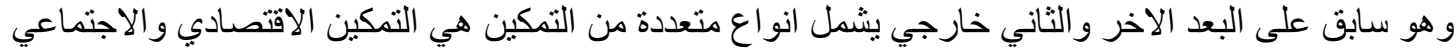

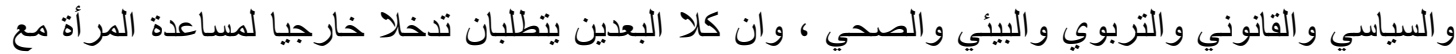

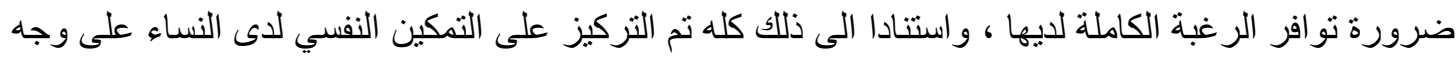

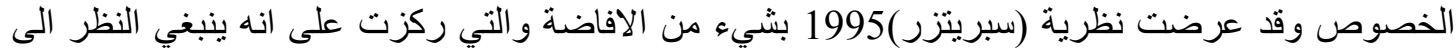

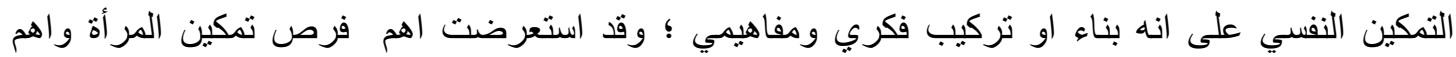

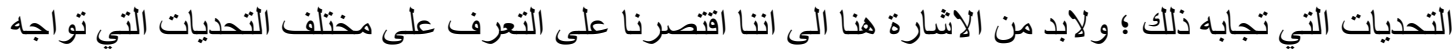

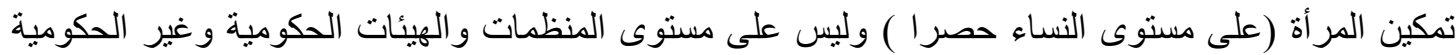

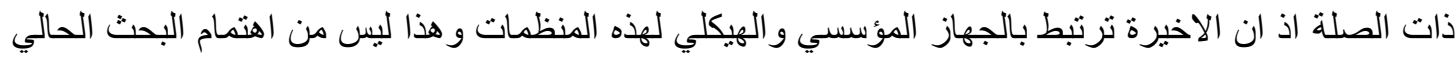
، وفي ضو ذ ذلك كله خلص البحث الى جملة من الاستتناجات و التوصيات و المقترحات . 


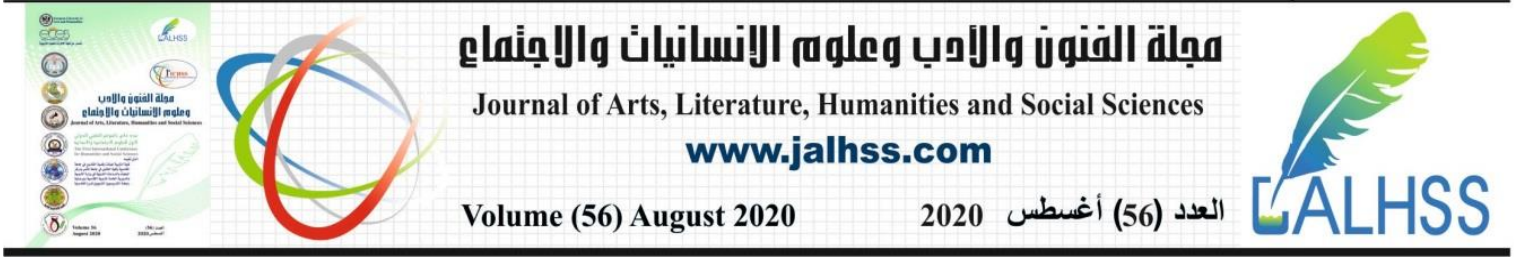

\title{
Empowering women ... Opportunities and Challenges
}

\author{
Dr. Siham Mutasher A-Kaapy \\ Director of the Center for Women's Studies - University of Baghdad - Iraq \\ Email: Email :dr.sihamalk@gmail.com \\ Siham.mtashar@wsc.uobaghdad.edu.iq
}

\begin{abstract}
The subject of empowering women in the twenty-first century has become a hot issue around the world. Modern women are searching for equal opportunities with men and the two are competing strongly in various fields such as politics, economics and other social sectors. The results of many studies have shown that women around the world today stand on an equal footing with men; it is undeniable that some women are much better than men when it comes to some issues. Possible women contribute to the development of their country's economic, social and political status, and women make up about $50 \%$ of the world's population, and they represent the backbone of the development of their countries. On the other hand, according to the American Center for Leadership Women, the overall integration of women in the economic life of the state is essential for the welfare of society, however, this matter remains somewhat unattractive to it.

In light of what was proposed in the current research, it was concluded that there are two dimensions of the first internal empowerment which is psychological empowerment and it is a precedent to the other dimension and the second is external that includes multiple types of empowerment are economic, social, political, legal, educational, environmental and health, and that both dimensions require external intervention to help women with the necessity Having the full desire for it, and based on all of this, a focus was placed on psychological empowerment among women in particular. The 1995 Spritzer theory was presented with some elaboration, which focused on that psychological empowerment should be seen as a building or an intellectual and conceptual structure; I reviewed the most important opportunities for women's empowerment and the most important challenges that confront this; it must be noted here that we have confined ourselves to identifying the various challenges facing women's empowerment (exclusively at the level of women) and not at the level of relevant governmental and non-governmental organizations and bodies as the latter are related to the institutional and structural apparatus of this Organizations This is not of interest to the current research, and in light of all this the research concluded a set of conclusions, recommendations and proposals.
\end{abstract}

Keywords: empowerment, empowerment of women, opportunities, challenges. 
اصبح موضوع تمكين المر أة في القرن الحادي و العشرين قضية ساخنة حول العالم ؛ فالمر اة الحديثة تبحث

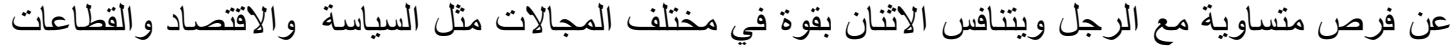

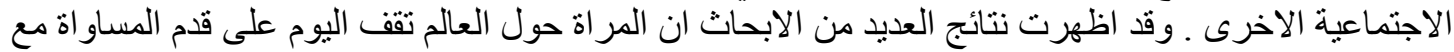

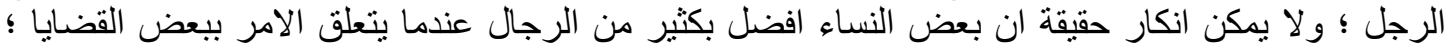
فالنساء القويات يسهمن في تتمية وضع بلدهن الإنتصادي و الاجتماعي و السياسي(Narayanan,2017,p.90).

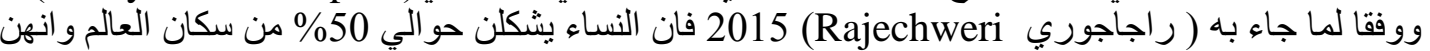

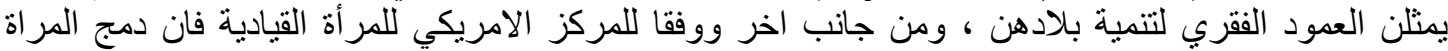

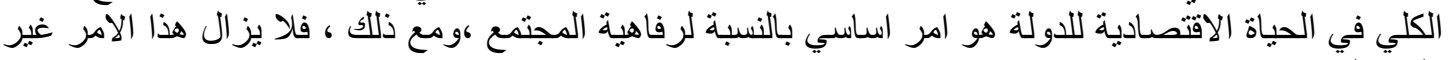
ملتفتا اليه بدرجة ما (Narayanan,2017,p.90). ان مصطلح تمكين المر اة اصبح من القضايا المثيرة للجدل في مجال التنمية ؛ ومن المسلم به انه امر الساسيا

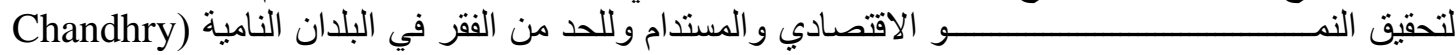
(,Lodhi,2012,p.171 ,Nosheen ظهر مفهوم التمكين Empowerment في الربع الاخير من القرن الماضي تقريبا كونه احد المفاهيم

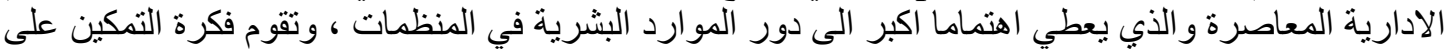

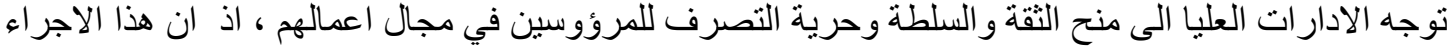

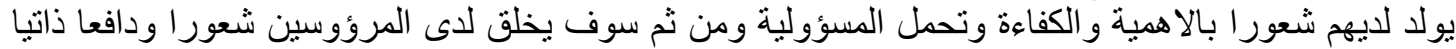

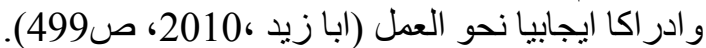

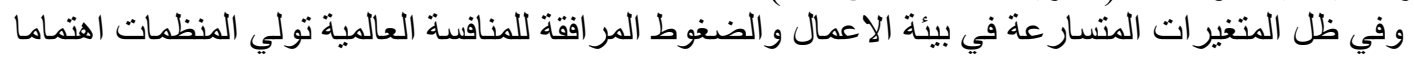

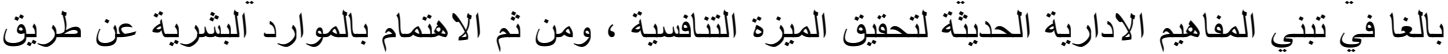

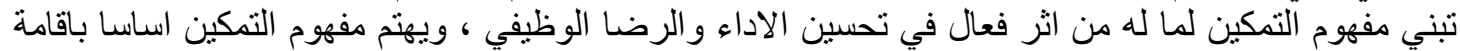

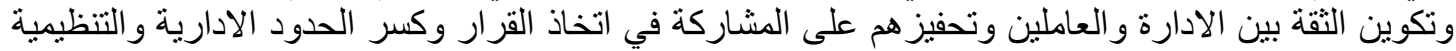

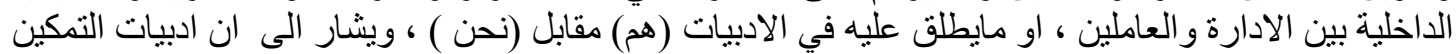

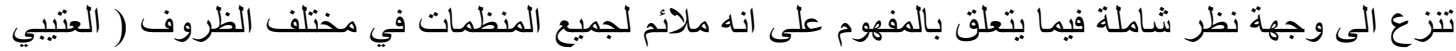

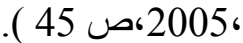

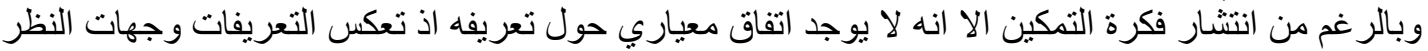

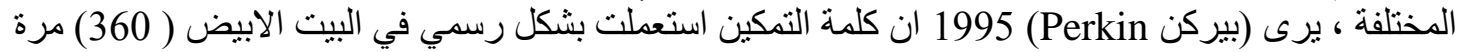

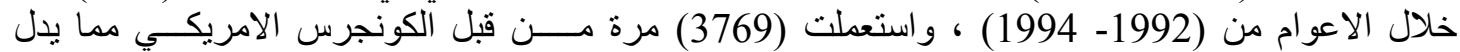

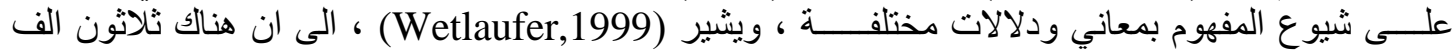

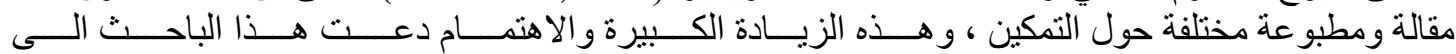

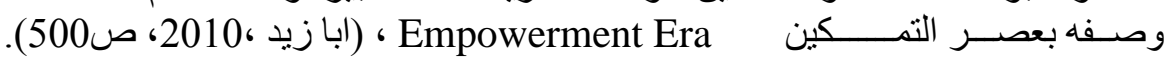

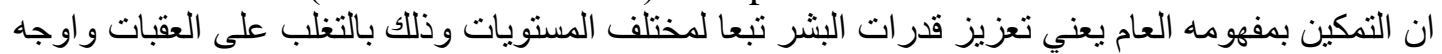

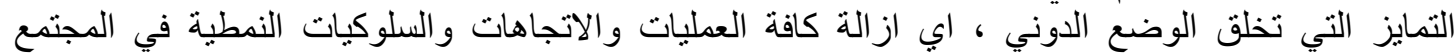
و المؤسسات التي تنمط النساء وتضعهن في مر اتب ادنى ، وذللك باكتسابهن القدرة على اتخاذ التهاذ القرار الت الت المتعلقة بحياتهن (حسن ، 2010 ( 2010 ). ان فكرة التمكين تجذرت في ايديولوجية الفعل الاجتماعي Social actionفي عقد الستينيات وضمن منظور ات رعاية الذات Self-help perspectives في عقد السبعينيات

.( Aujoul\&Hoore\&Deccache, 2006, p.8)

ظهر مصطلح التمكين في علم النفس المجتمي Community Psychology و اقترن مع العالم الاجتماعي

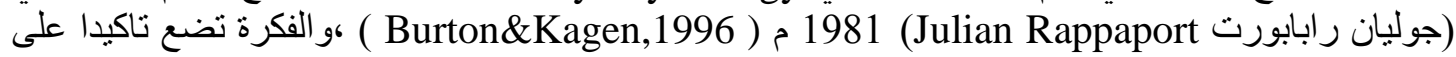

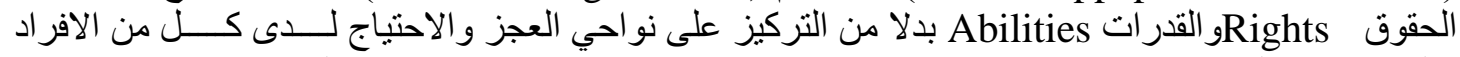

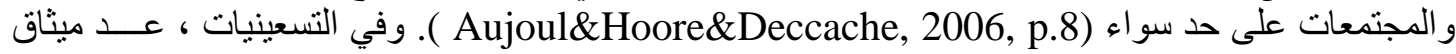
(اوتاوا) لتعزيز الصحة التمكين على انه قضية اساسية في نظرية تعزيز الصحة والذي ركز على تعزيز الصحة 


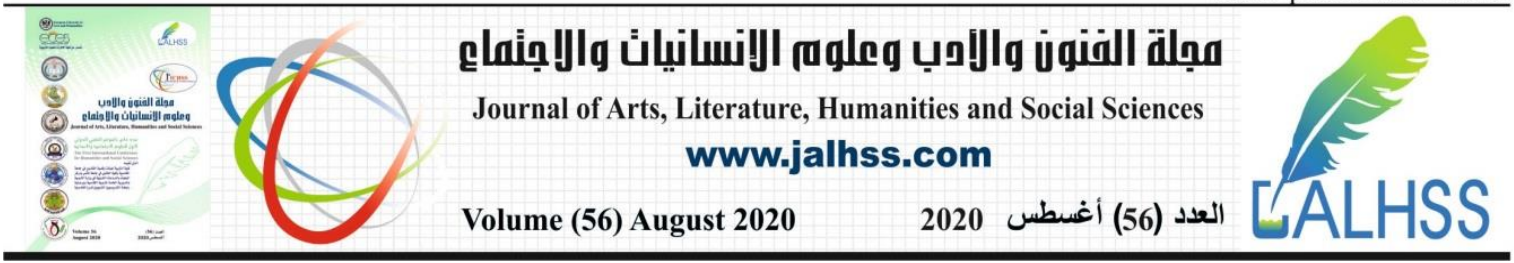

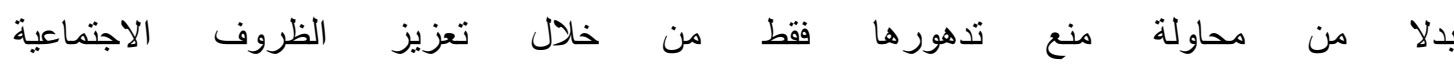
(Aujoul\&Hoore\&Deccache,2006,p.3)

و هو يشير الى تدابير ترمي الى زيادة درجة الاستقلال الذاتي وتقرير المصير لأى الافراد و المجتمعات بغية

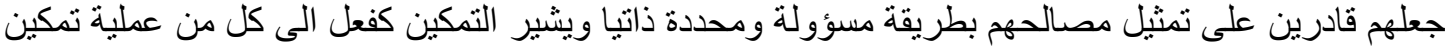

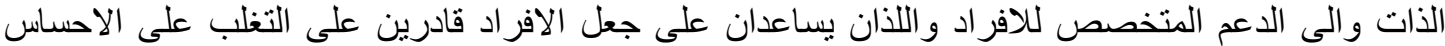

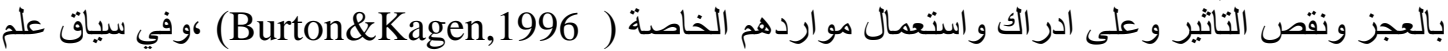

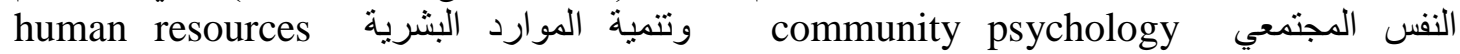

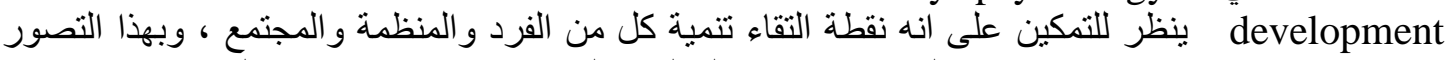

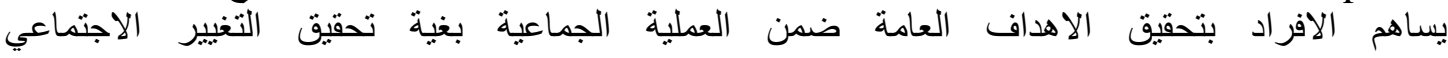
.(Aujoul\&Hoore\&Deccache,2006,p.)

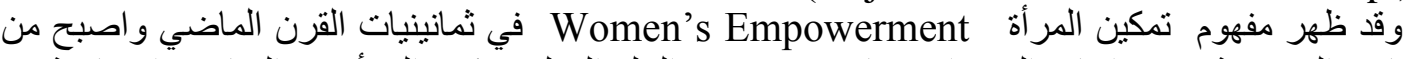

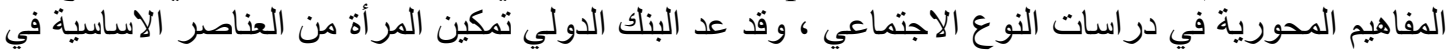

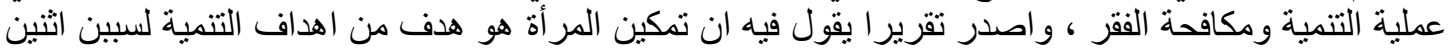

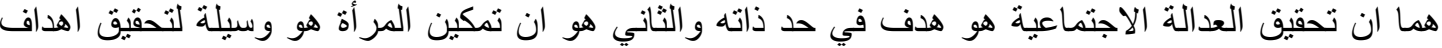

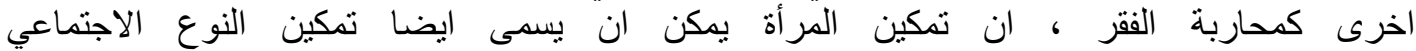
.(Mishra,2016,p.224) Gender Empowerment

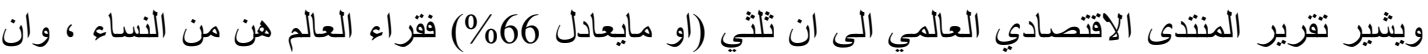

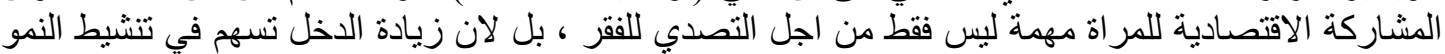

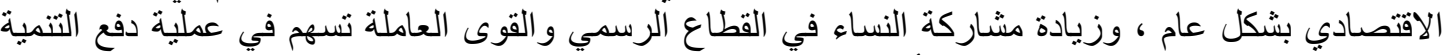

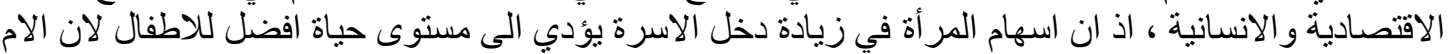

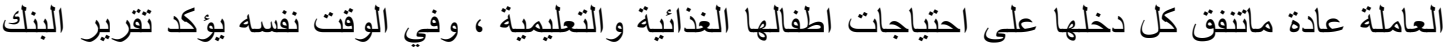

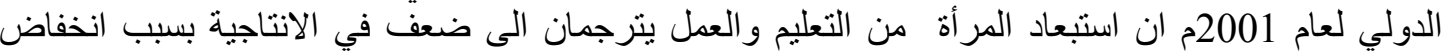

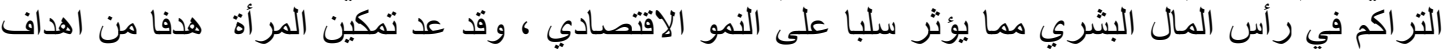

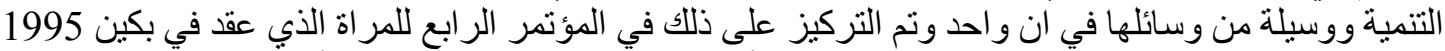

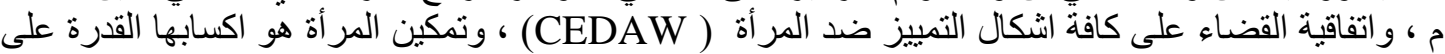

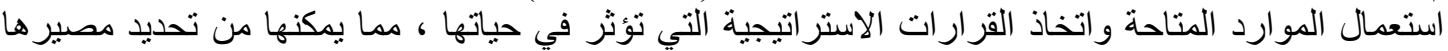

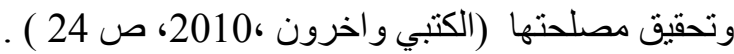

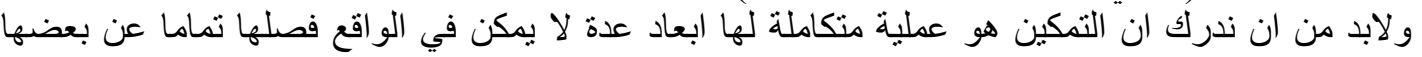

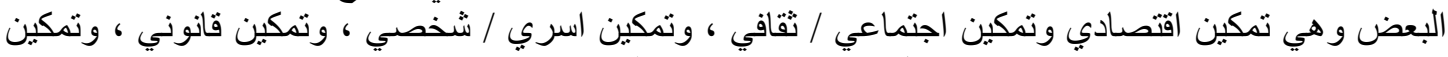

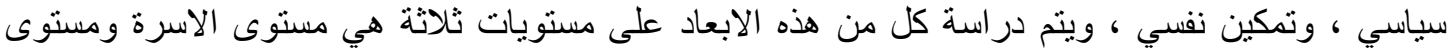

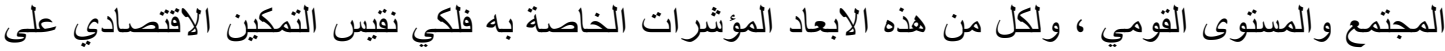

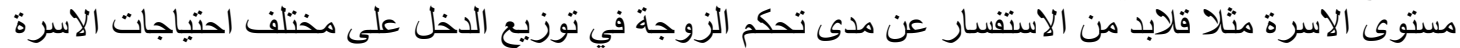

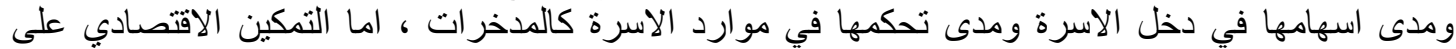

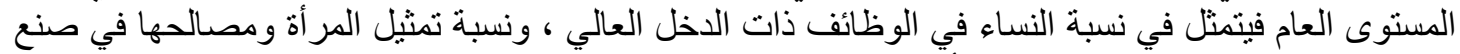

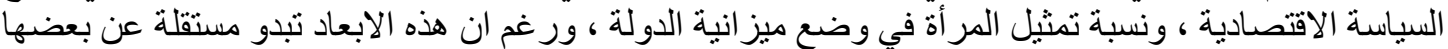

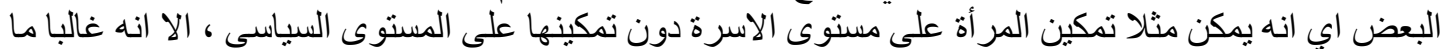

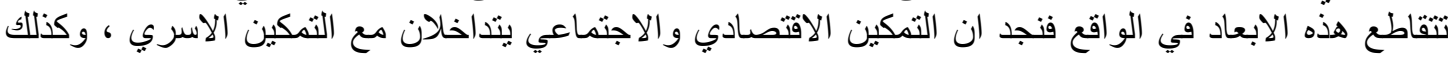

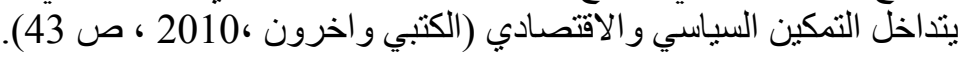

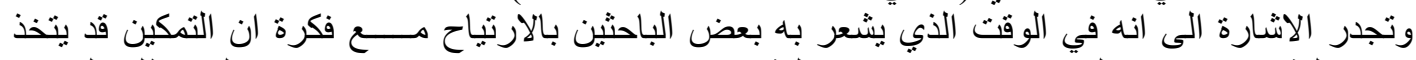

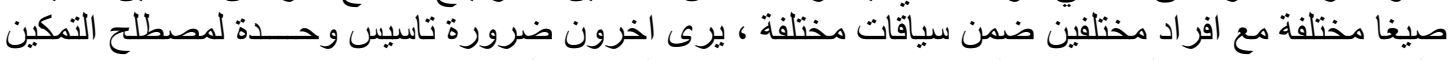

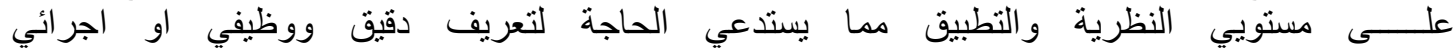
.(Aujoul\&Hoore\&Deccache,2006,p.) 


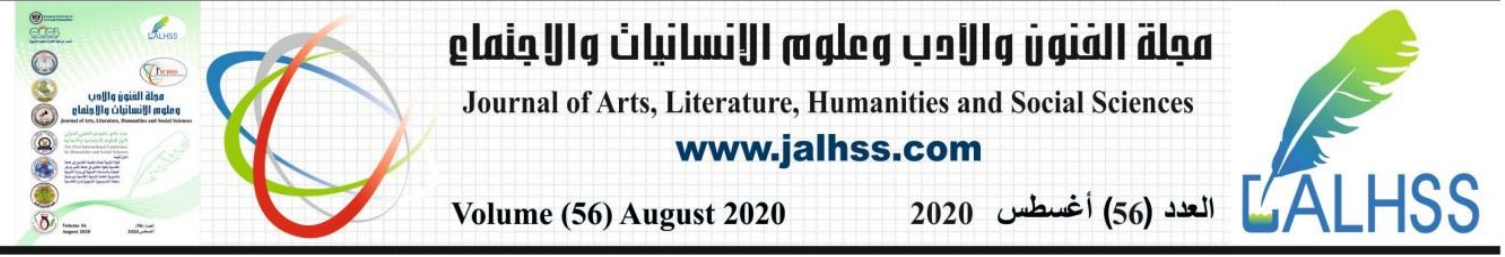

و التمكين لا ينطبق بالضرورة على النساء فقط ، بل يشمل جميع الافر اد و الجماعات المستضعفة او المهمشة في صفي

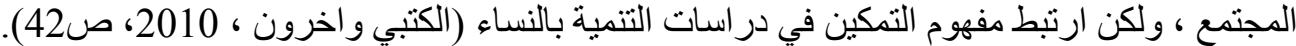

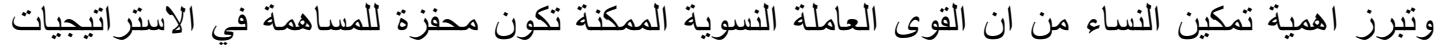

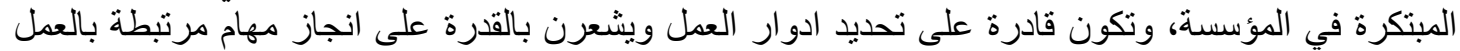

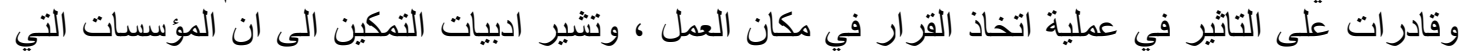

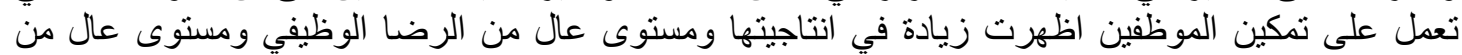

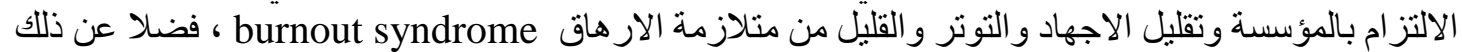

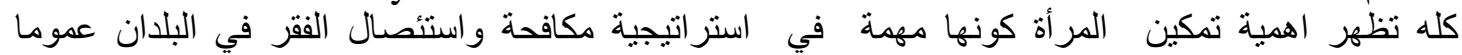

.(Mishra,2016,p.226) من ذلك كله ياتي البحث الحالي محاولة بهذا الاتجاه للكثف عن تلت تمكين المر أة و اهم فرص تحقيقه و ابرز التحديات التي تحول دون ذلك ؛ ؛ من خلال تفحص الادبيات والدراسات الحديثة عن الموضو عاد ومن ذلك تبرز

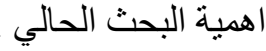

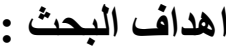

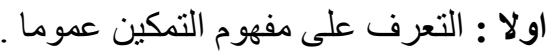

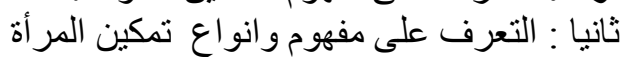

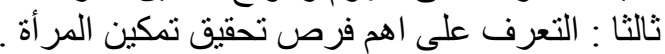

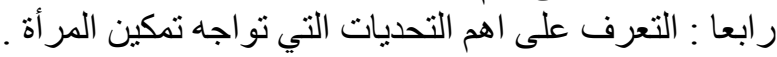

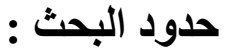

تحدد البحث بالادبيات التي تتاولت مفهوم تمكين المر أة باللغتين العربية و الانجليزية و التي استطاعت الباحثة

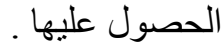
تحديد المصطلحات :سيتم تعريف المفهوم الرئيس و هو تمكين المر أة ؛على ان يتم التقديم له بتعريف التمكين

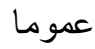

Empowerment اولا :التمكين 1- التمكين لغة : هو التقوية والتعزيز او الترسيخ او التثبيت ، ويقال (مكن من الثنيء) بمعنى جعل له عليه

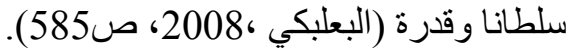
وردت كلمة التمكين في معجم لسان العرب بلفظ المكنة فيقال فلان ذو مكنة عند السلطان اي ذو تمكن ، و ومكين

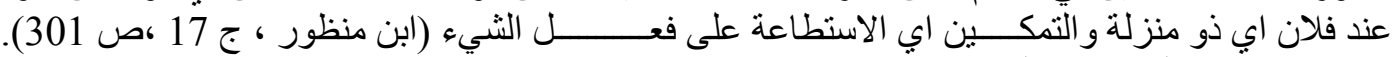

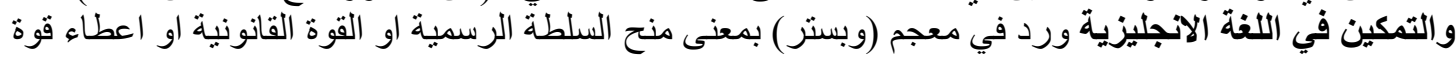

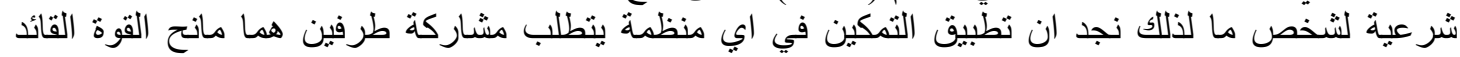

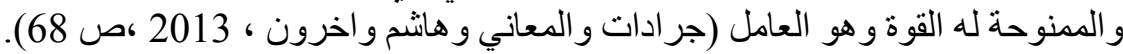

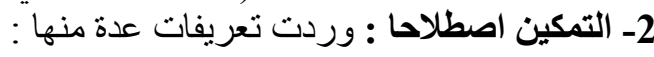

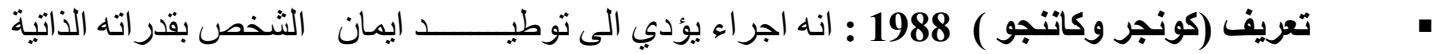

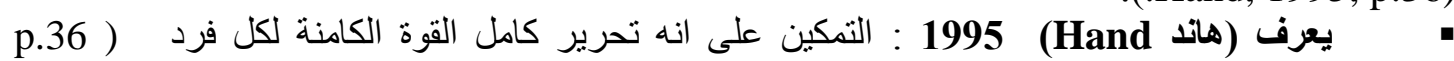
(Hand, 1995,

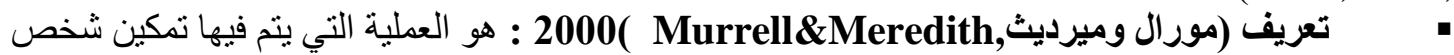
ما ليتولى القيام بمسؤوليات اكبر من خلال التدريب والثقة والدعم العاطفي ( (2000,p.110 تعريف (العديلي ) 2008 : عملية اتاحة الفرصة للاخرين في زيادة قدر اتهم الجماعية وتقديم افضل التهل مالديهم ، و هو استثمار قدر ات ومواهب الاخرين و اشعار هم باهميتهم لاثراء العمل الوظيفي (العديلي ،2008 ، 


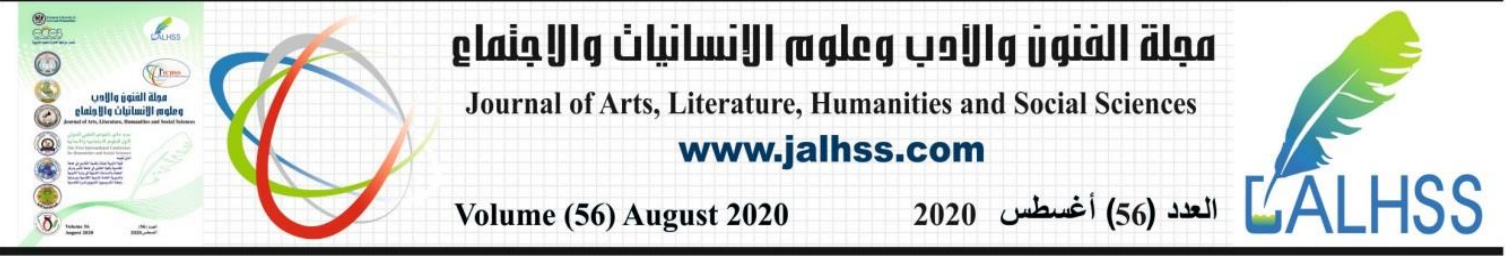

Women's Empowerment : ثانيا :تمكين المرأة وضعت تعريفات عدة لمفهوم تمكين المر أة كلها تدور حول فئ فكرة واحدة وهي تمكينها من اتخاذ القرارات

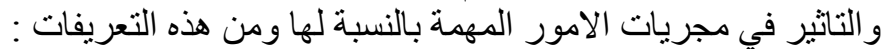

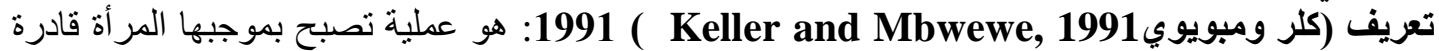

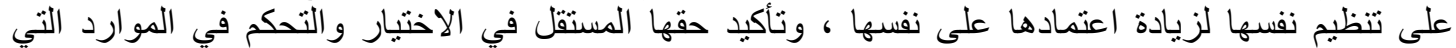

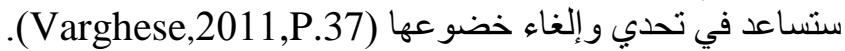
تعريف (بينيت ) 2002 : هو دعم امكانية المرأة وقدرتهاء وفيا على التاثير في المؤسسات الاجتماعية التي

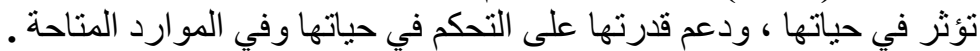

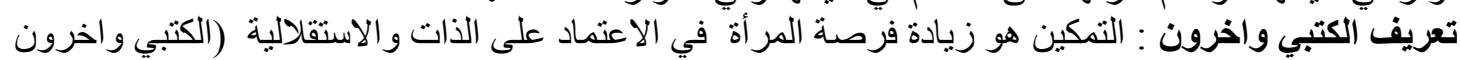

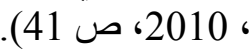
تعريف ( شتر 2015(Shettar) هو زيادة القوة الروحية او السياسية او الاجتماعية او التعليمية او الاقتصادية

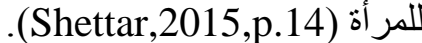
تعريف ( جيلتا واخرون (Geleta et al) 2017 : هو العمليات التشاركية participatory processes التي

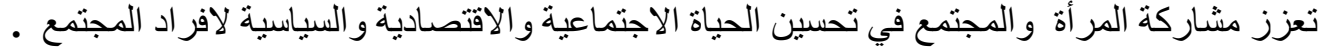

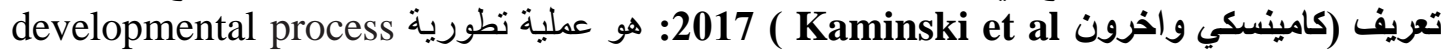
تعزز اسلوبا فعالا لحل المشكلات وتعمل على زيادة الفهم السياسي لدى المر أة وزيادة قدرتها على السيطرة على البيئة (Geleta et al ,2017,p.2).

لقد كرس الصندوق الانمائي للامم المتحدة عبر تقاريره محاور وابو اب خاصة للحديث عن موضوع المارع التمكين

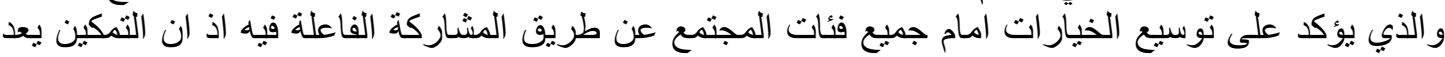

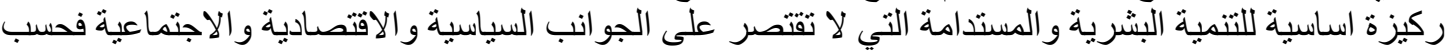

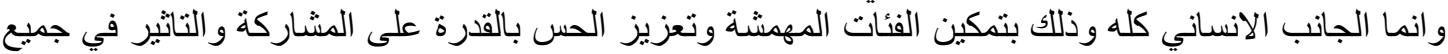

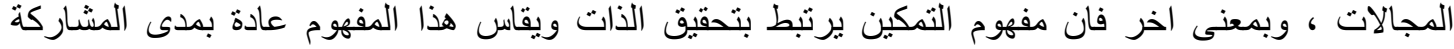

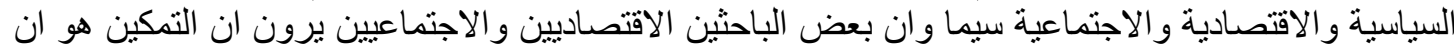

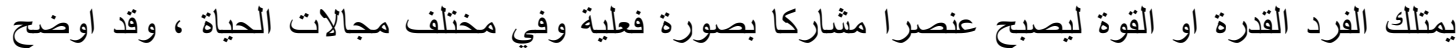

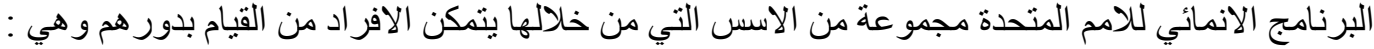

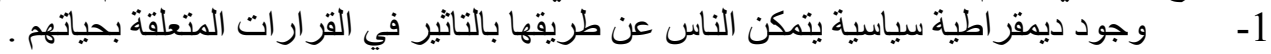

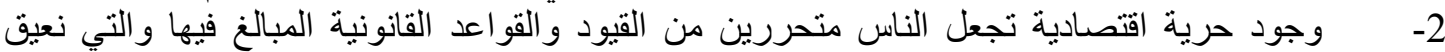

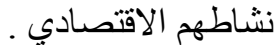

3- وجود سلُّة لا مركزية بحيث يتمكن كل مو اطن من المشاركة في ادارة حياته الوطنية والمحلية انطلاقا

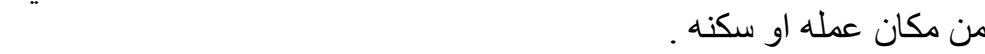
4- مشاركة جميع المواطنين سيما المؤسسات غير الحكومية في صنع القرار وتنفيذ خطط التنمية ( قاسم ،

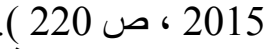

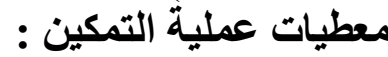

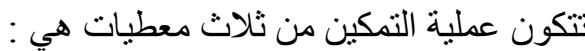
اولا : المواردResources: مثل العمل والتعليم وتعد هذه عناصر التمكين اي ان وجودها ضروري وبدونها

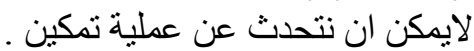

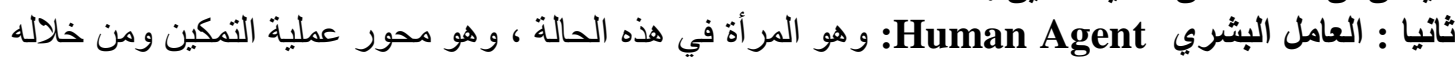

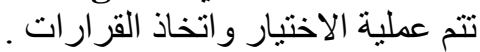

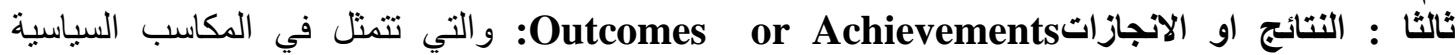
و الاقتصادية والاجتماعية التي تجنيها المرأة وهي بمثابة المؤشرات التي يمكن على اساسها قياس مدى نجاح عملية التمكين ( ملحم ، 2006 ،صاعنة تصنية 


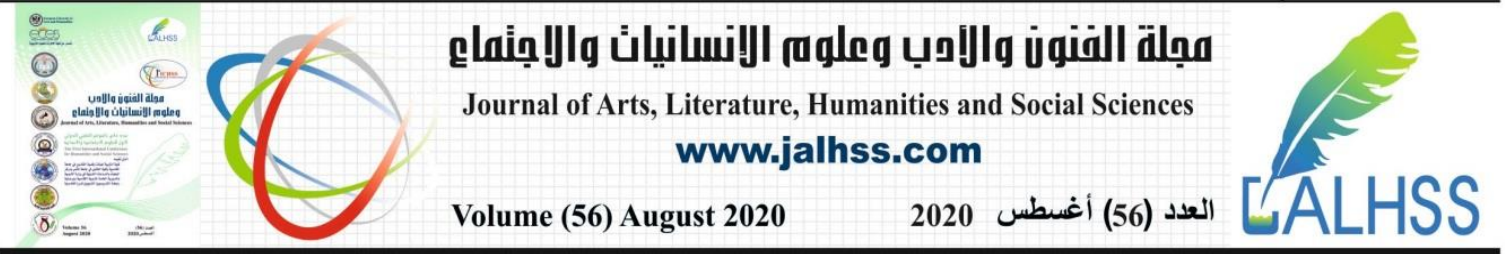

وتكمن المشكلة في صعوبة قياس التمكين ، اذ انه عملية كما اثشير الى ذللك اعلاه ، ومن الممكن قياس نتائج

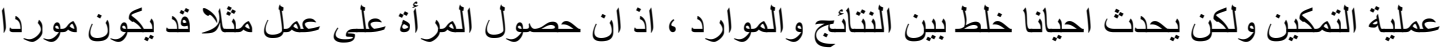

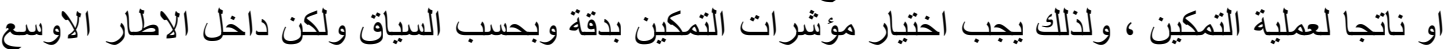

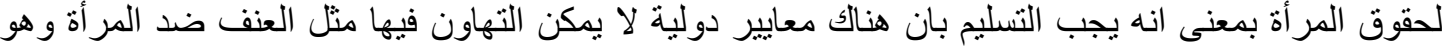

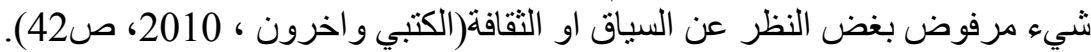

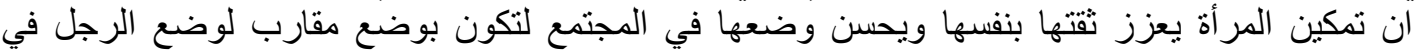

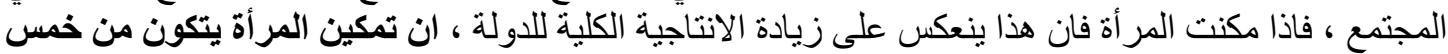

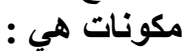

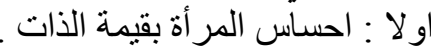

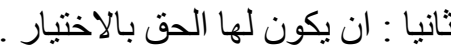

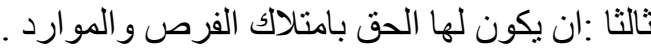

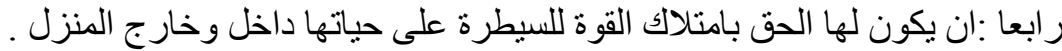

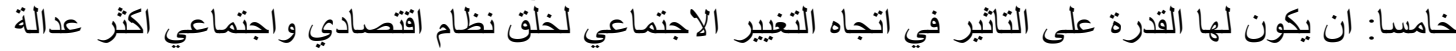

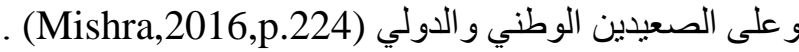

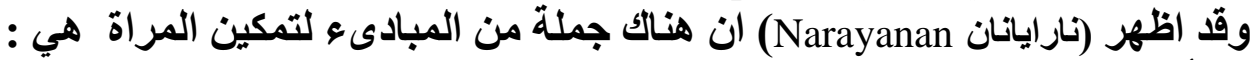

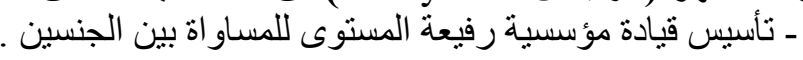

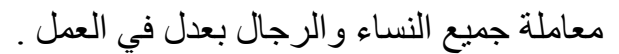

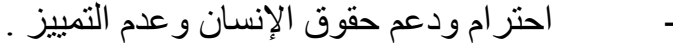

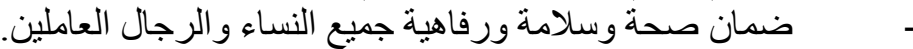

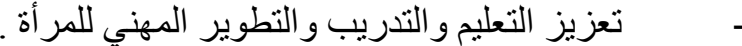

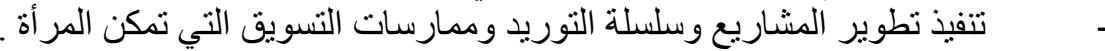

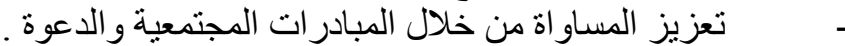

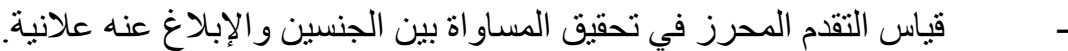

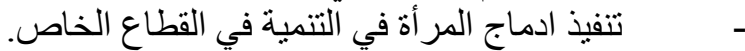

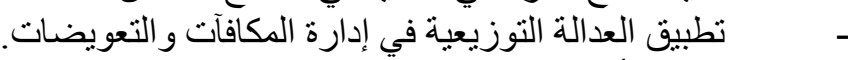

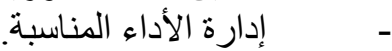

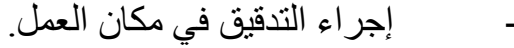

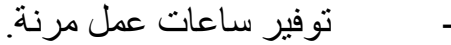
-

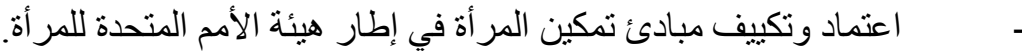
من خلال كل ما سبق ، يصبح تمكين المر أة هدفا يمكن تحقيقه (Narayanan,2017,p.94).

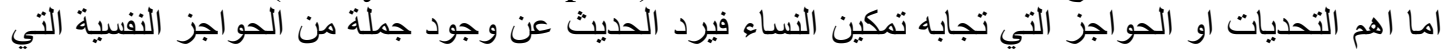

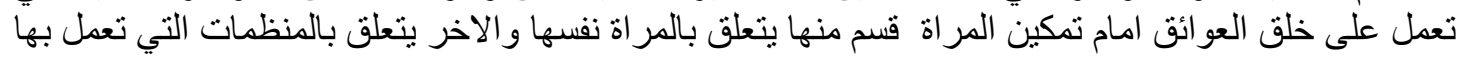

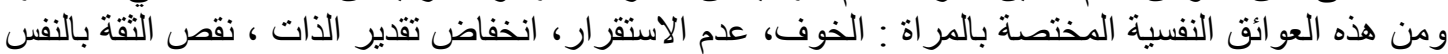

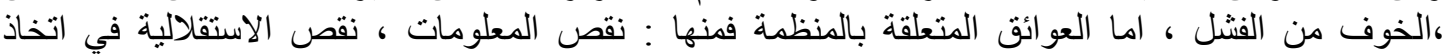

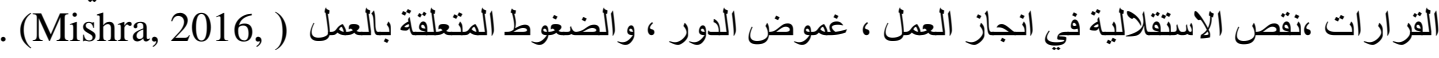

هناك محاو لات مختلفة في الأدبيات لتطوير فهم شامل للتمكين من خلال تقسيم العملية إلى مكونات رئيسية؛

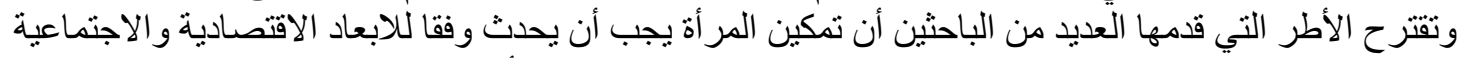

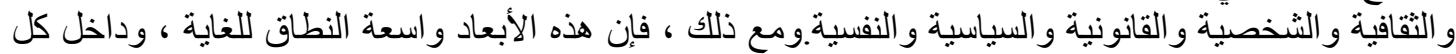

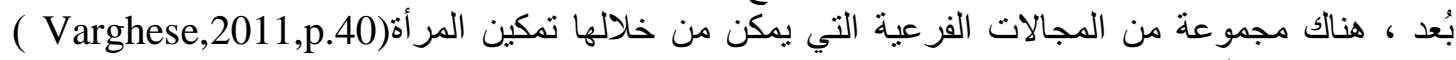

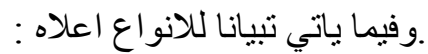




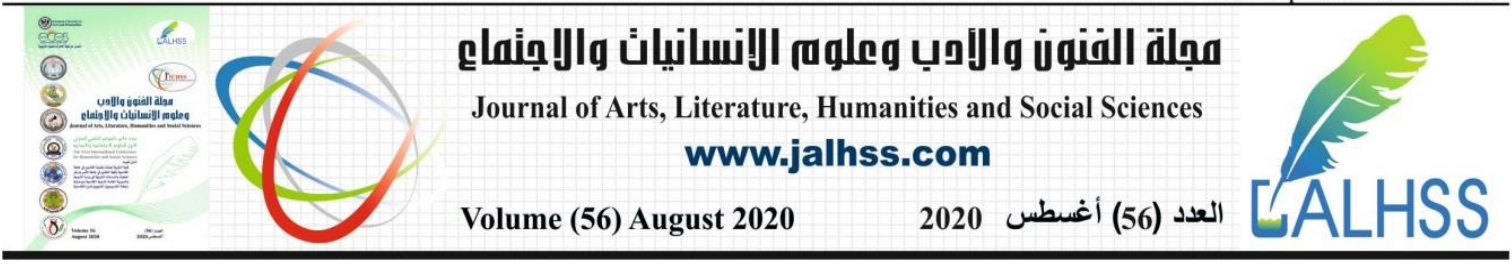

Economic Empowerment : اولا : التمكين الاقتصادي ويتم هذا التمكين عن طريق النصيب النسبي لكل من الرجل والمبن المراة في مختلف الوظائف الادارية والتنظيمية

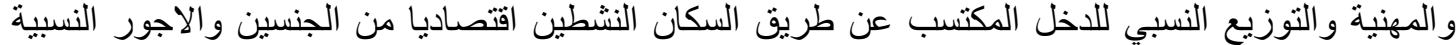

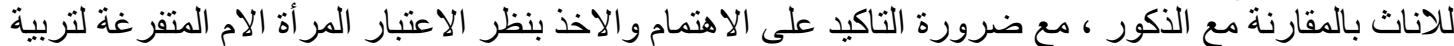

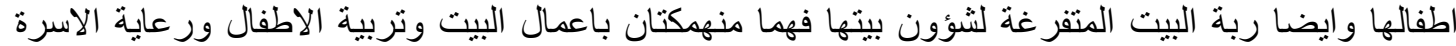

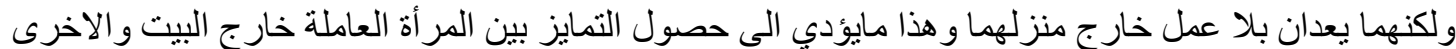

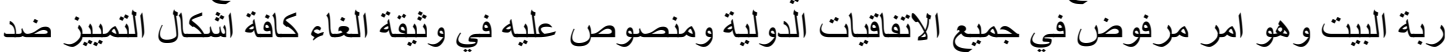

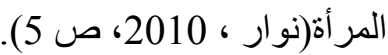

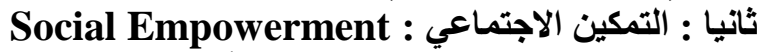

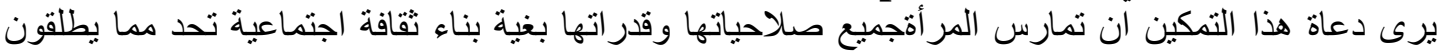

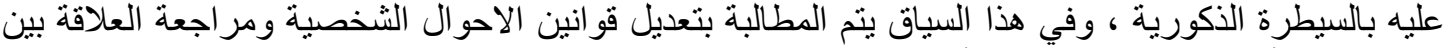

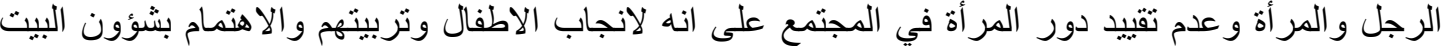

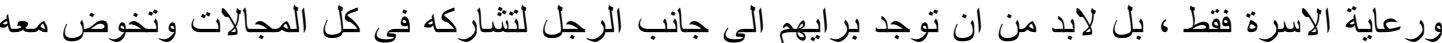

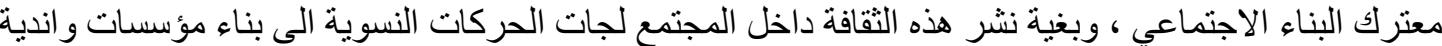

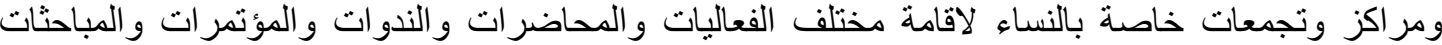

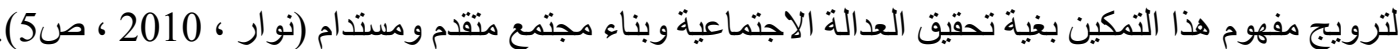

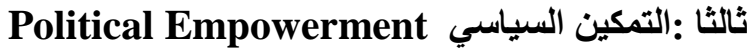
على وفق اراء الداعين لهذا النوع من التمكين فانه يقاس بعدد المقاعد البرلمانية المنوافرة او المتاحة للرجال

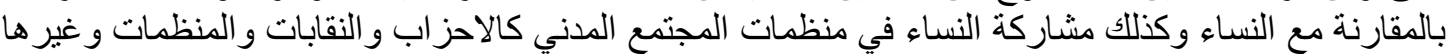

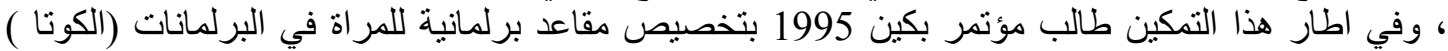

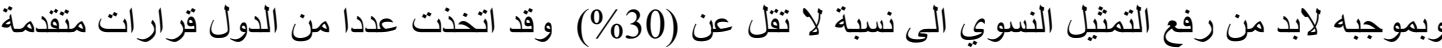

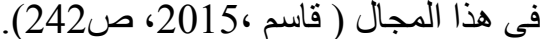

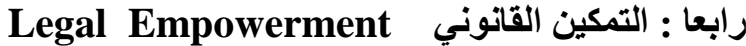

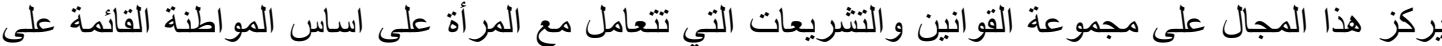

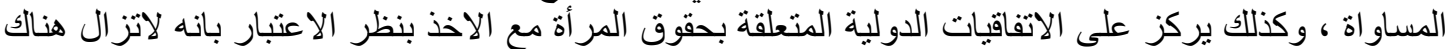

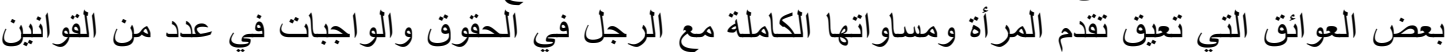

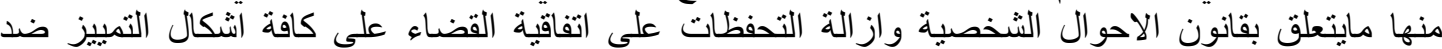

المرأة(السيداو ) (Mishra,2016,p.224).

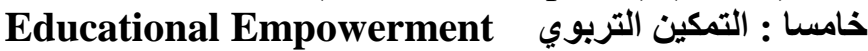

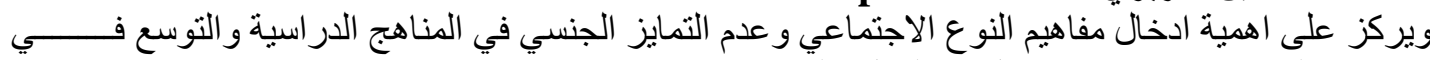

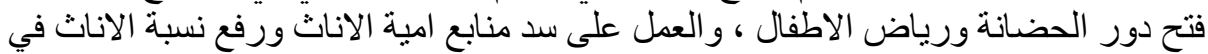

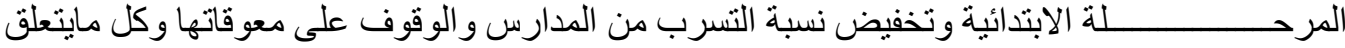

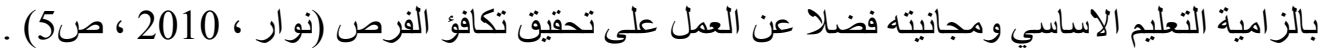

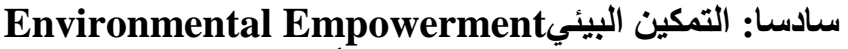

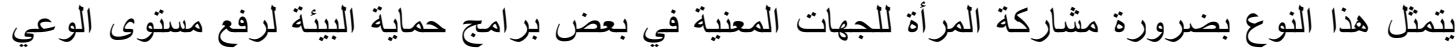

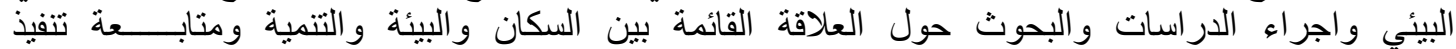

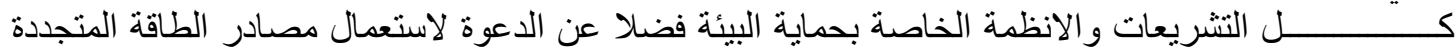

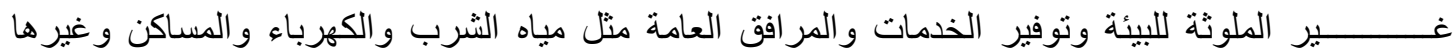

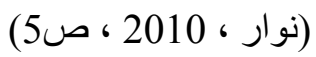

سابعا: التمكين الصحي Health Empowerment

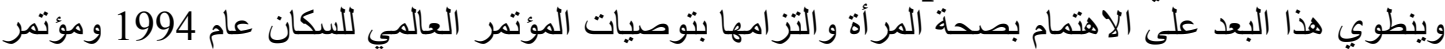

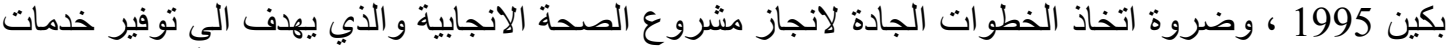

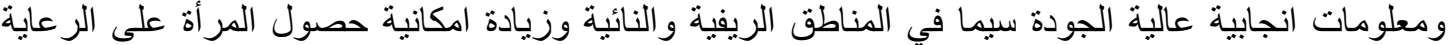
الصحية و المعلومات و الخدمات ذات العلاقة بحيث تكون ملائمة وذات نو عية جيدة (قاسم ،2015، صالنة ص244) 


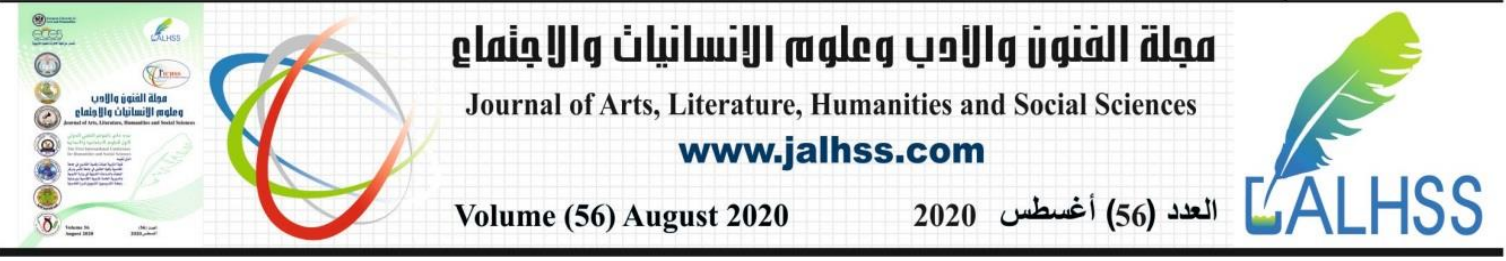

Psychological Empowerment

ثامنا :التمكين النفين

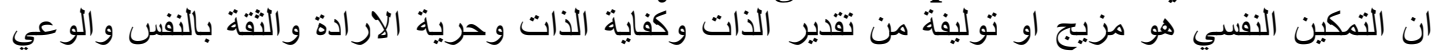

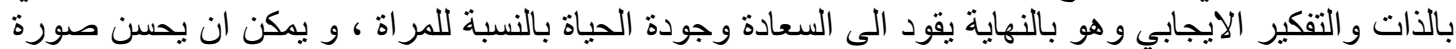

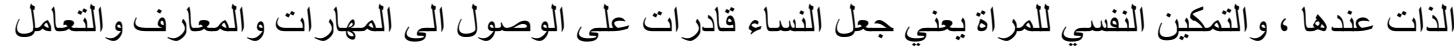
مع الضغوط و الصدمات سواء في الوقت الحالي او في المستقبل ( Randolph \&(Mishra,2016,p.225 ) . and Sashkin, 2002)

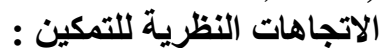
لقد جاء مفهوم التمكين Empowerment في الفكر الاداري ليطالب بالتخلي عن عن النموذج التقليدي للقيادة

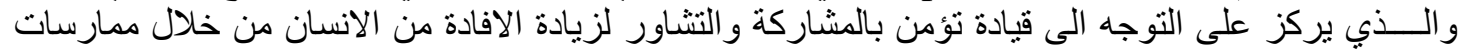

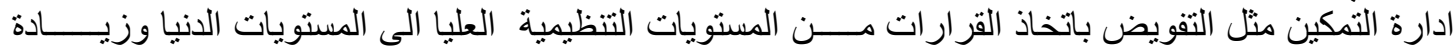
الوصول الى المعلومات و المو ارد للافر اد في المستويات الدنيا (S preitzer,1999.p.1443). وقد ادى تر اكم المعرفة الناتج عن در اسة ابعاد متعددة للتمكين الى ظهور التهاهات التهات عدة في در استه ، سمحت

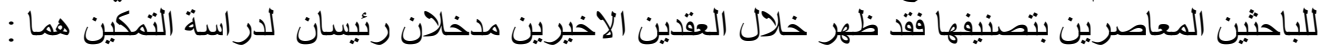

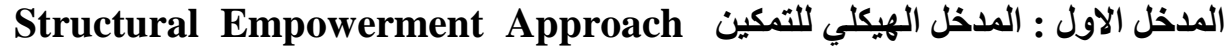
و هو مدخل كلي يركز على الممارسات التي تعمل على تفويض الملى الصلاحيات ومنح القوة او ادوات القوة من

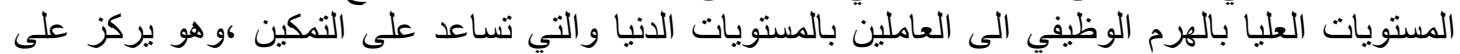
الظروف التي تساعد على التمكين في بيئة العمل ومن ثم فان هذا المدخل ينص التص على النى الن القوة تكمن بالتساوي

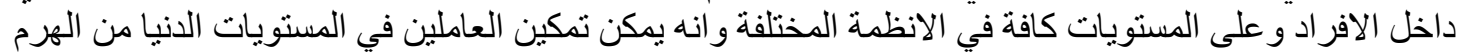

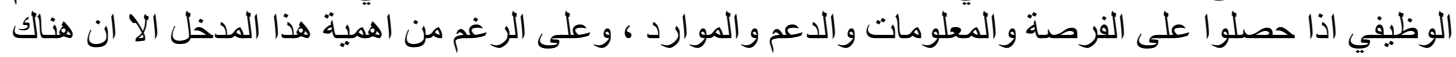

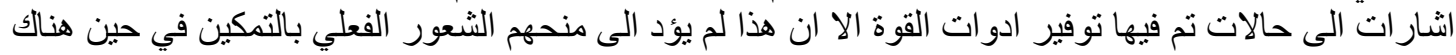

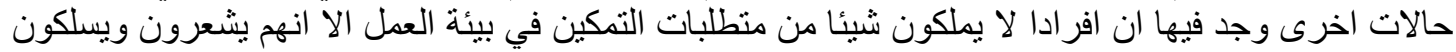
باسلوب وطريقة الافر اد الممكنين و هذا التحديد ساعد في ظهور مدخلا اخر هو مدخل التمكين النفسي (جر ادات

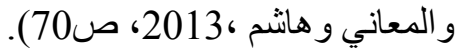

Psychological Empowerment Approach المدخل الثاني : مدخل التمكين النفسي

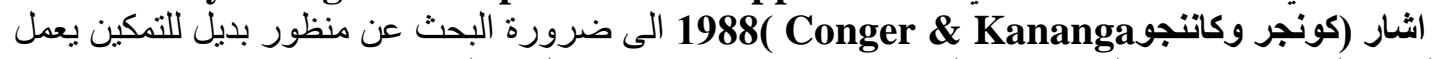

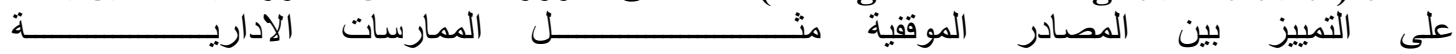

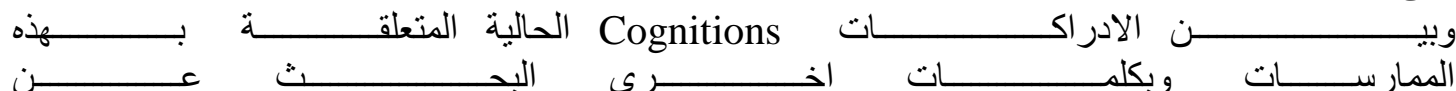

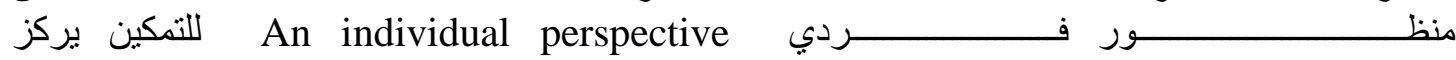

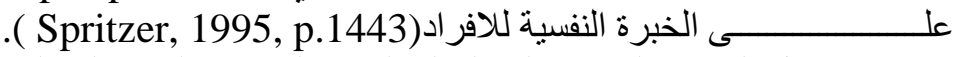
يركز مدخل التمكين النفسي على الحالة النفسية للافر اد وليس على البناء الاجتماعي او الممارسات الادارية ،

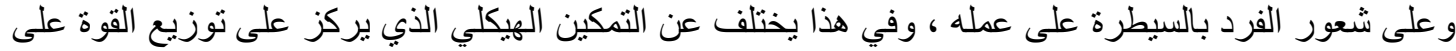

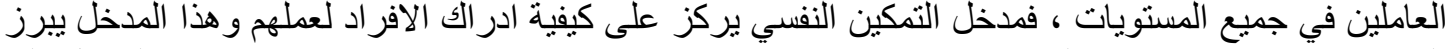

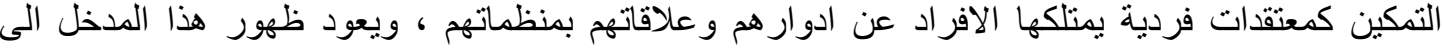

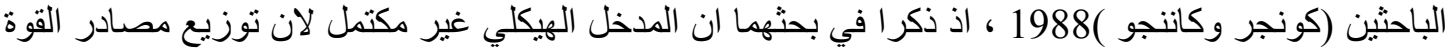

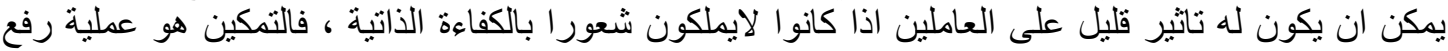

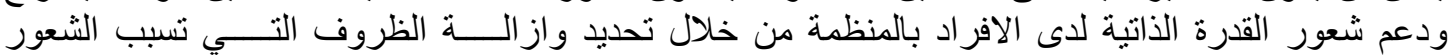

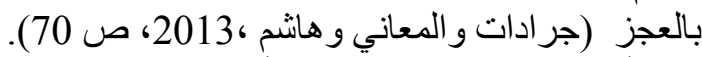
بعد ذلك جاء كل من (توماس وفأهاوس 1990)Thomas\& Velthous و اتما افكار (كونجر وكاننجو )من خلال تطوير اطار نظري يعبر عن التمكين ، اذ يعتقدان ان التمكين هو مفهوم متعدد الاوجه و

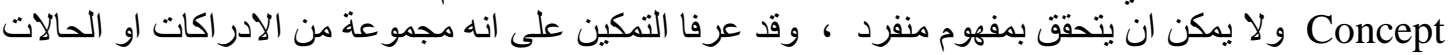

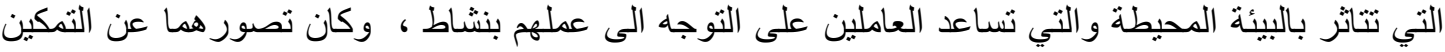

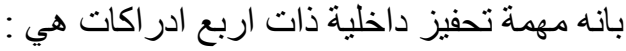




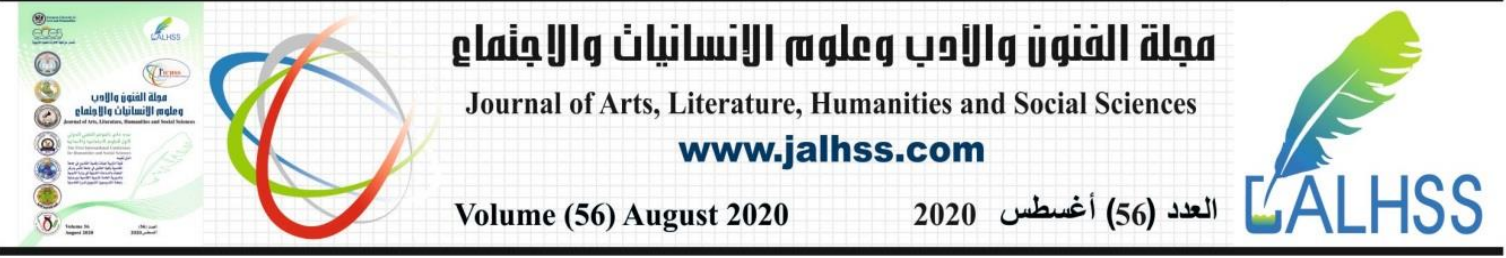

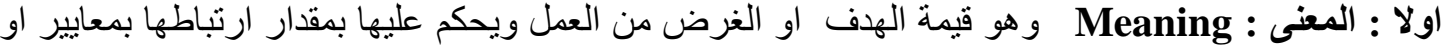

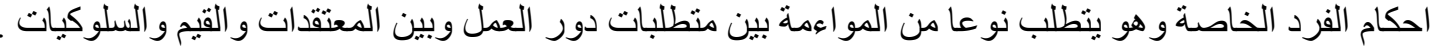
ثثاتيا : الكفاية Competence او الكفاية الذاتية : وهي اعتقاد الفرد بقدرته على تنفيذ النشاطات بمهارة وهي

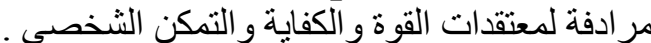

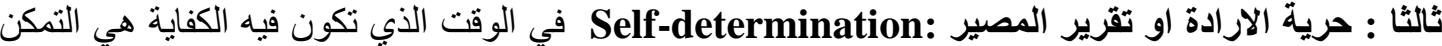

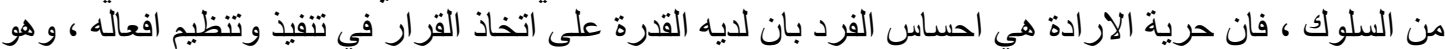

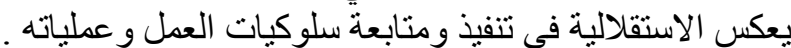

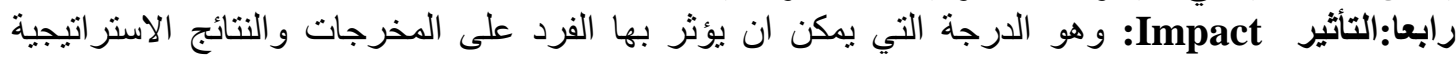

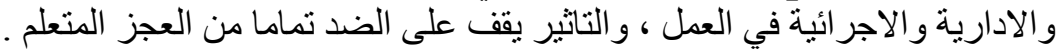
(Thomas\&Velthouse,1990,p.666) و هكذا نجد ان الباحثين ينظران الى التمكين على انه بناء دافعي يتجلى في اربع ادر اكات هي الإني (المعنى و الكفاية

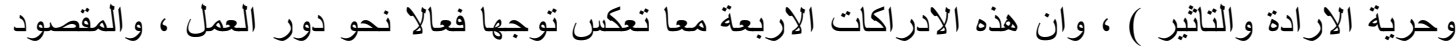

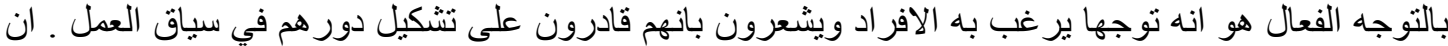

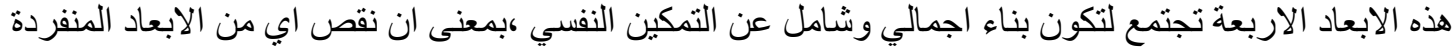

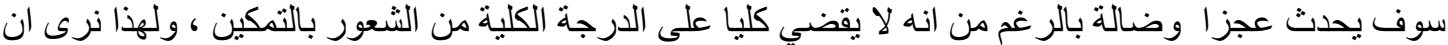
الابعاد الاربعة هي تقريبا مجموعة كاملة وكافية من الادر اكات لفهم التمكين النفسي( (Spreitezer, 1995 ). p.1444

وفي عام 1995 قامت (سبريتزر

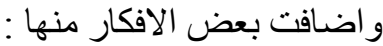

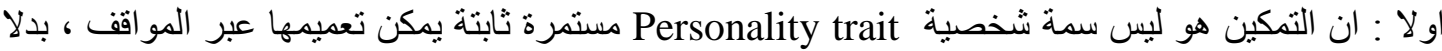

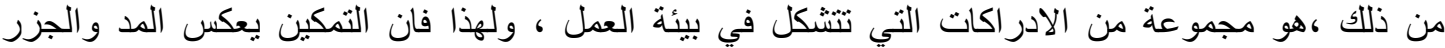

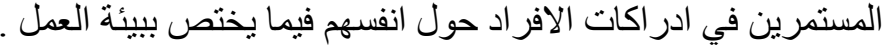

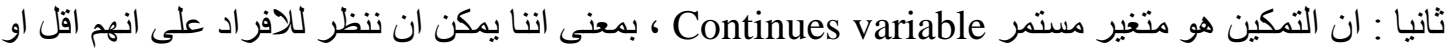

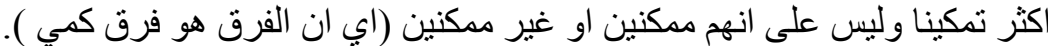

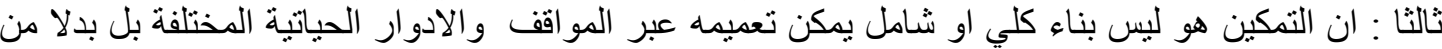

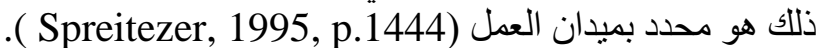

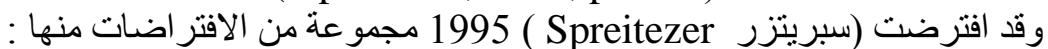
او لا : ان هناك اربعة ابعاد متمايزة للتمكين النفسي هي (المعنى و الكفاية وحرية الار ادة و التاثير ) وانية وان كل بعد من

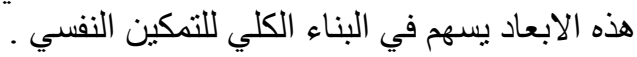

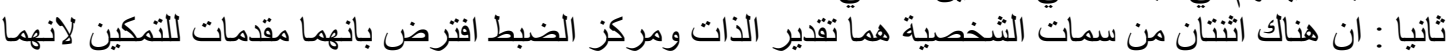

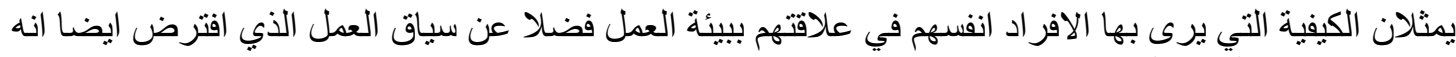

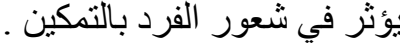
ثالثا : ان هناك نتيجتان للتمكين النفسي هما الفاعلية الادارية وسلوك الابتكار ،ويمكن توضيح ذلك بالثكل ( 1). 


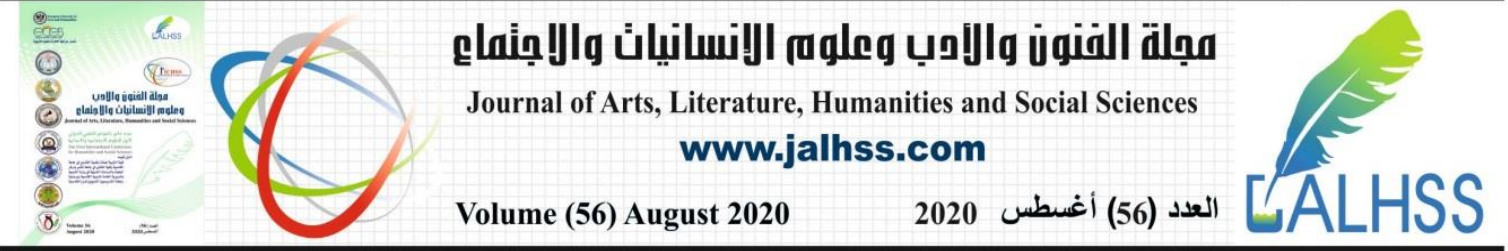

مقدمات التمكين

مخرجات التمكين

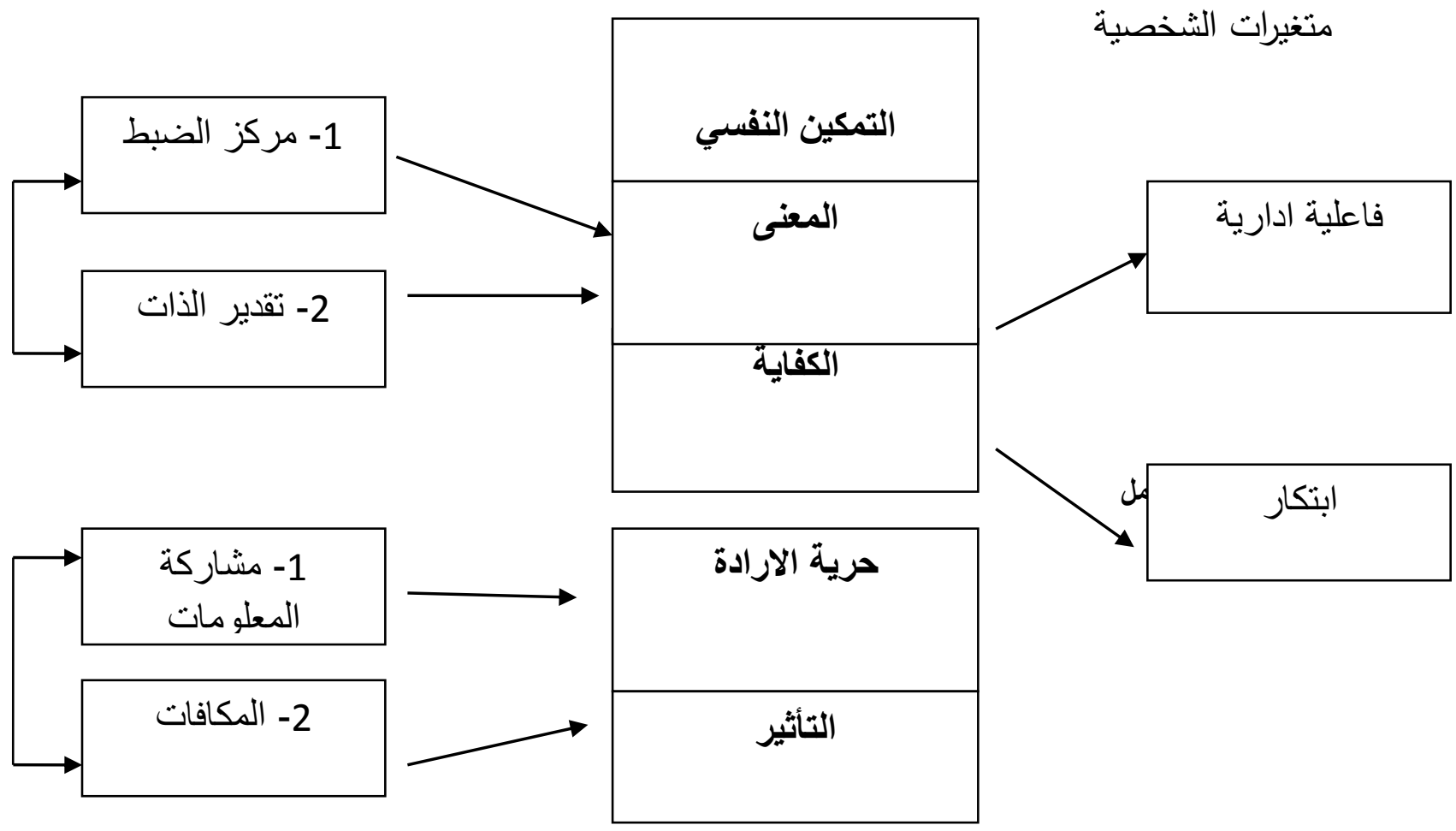

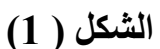

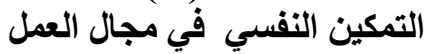 \\ مقدماته وابعاده ونتائجة بحسب نظي فجرية (سبريتزر)}

وقد افترض ان تقدير الذات ومركز الضبط الداخلي يرتبطان ايجابا بالتمكين النفسي و انهما وان كانا يشكلان

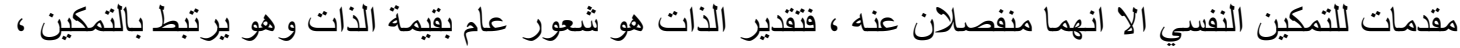

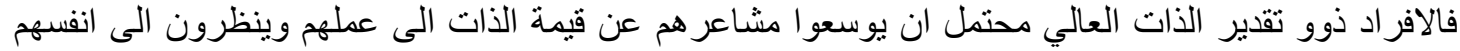

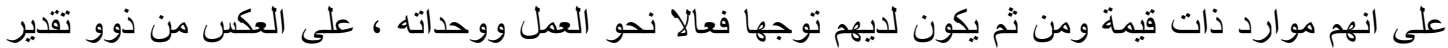

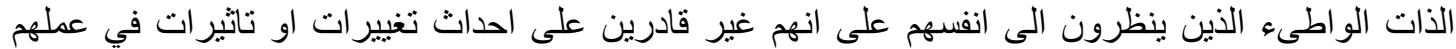

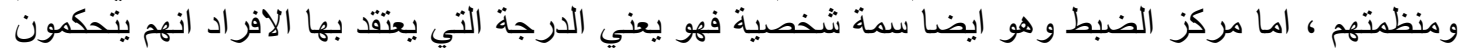

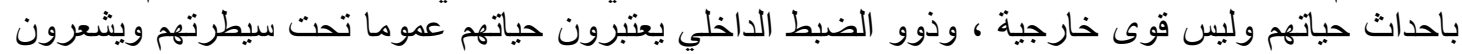

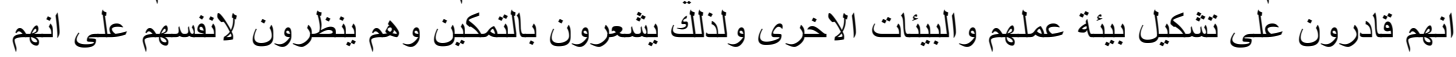

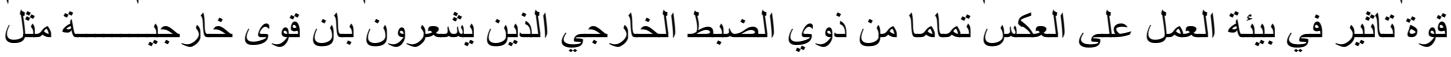

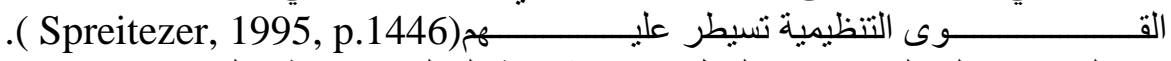

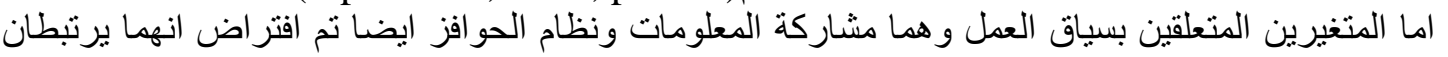

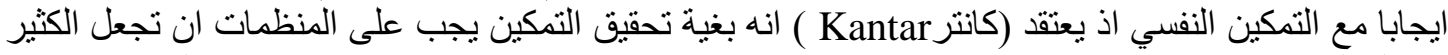

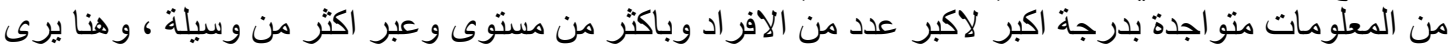

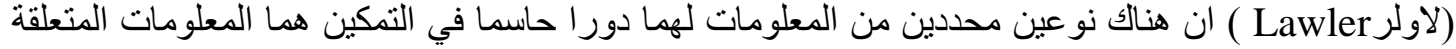

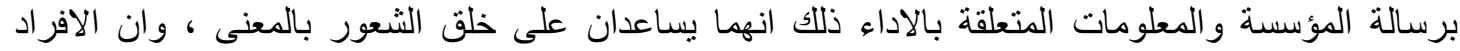




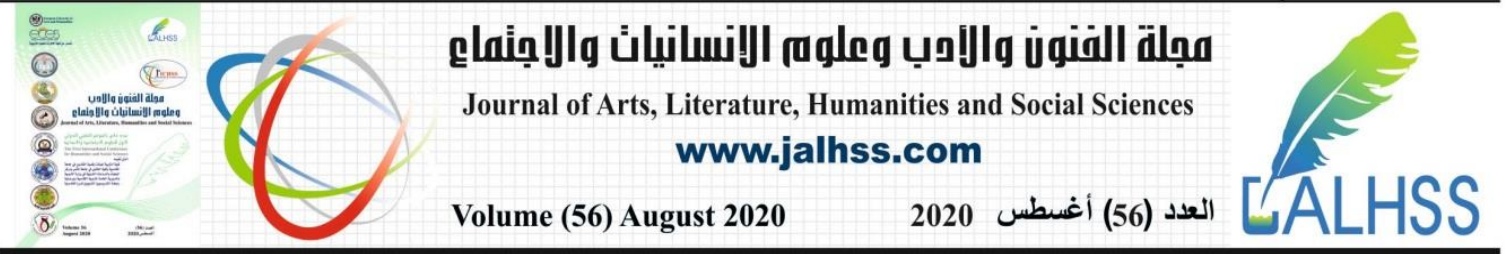

يحتاجون لفهم جودة مايقومون به من اجل اتخاذ القرارات و التاثثر بها لادامة وتحسين الاداء في المستقبل ، ). Spreitezer, 1995, p.1448)

\section{الاستتناجات والتوصيات والمقترحات}

اولا : استنتاجات البحث :

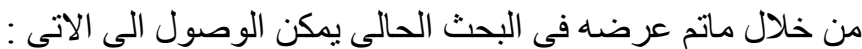

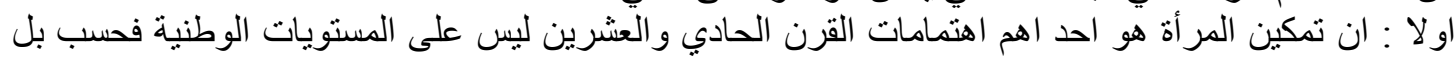

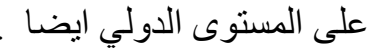

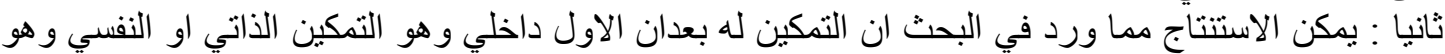

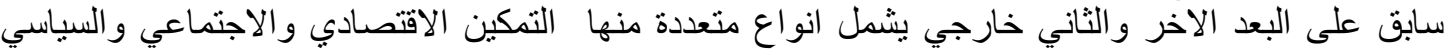

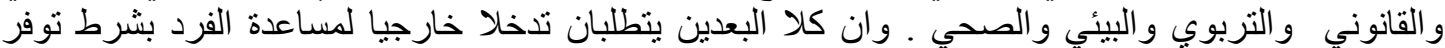

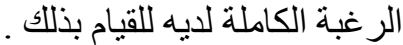

ثالثا : تمثل نظرية (سبرينزر ) 1995 عن التمكين النفسي التيار النفسي لتناول المفهوم ووفقا لهذا التيار ينبغي

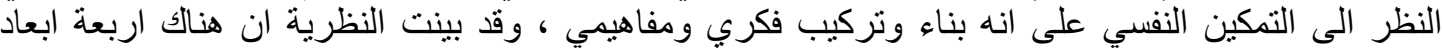

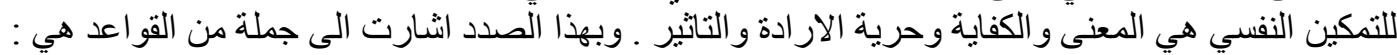

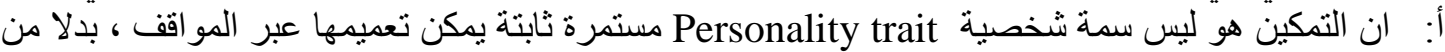

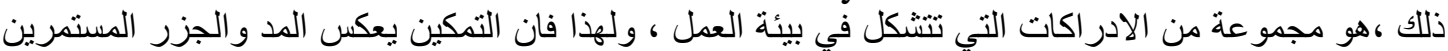

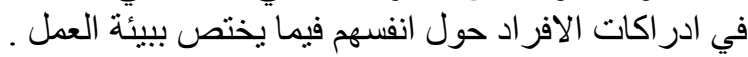

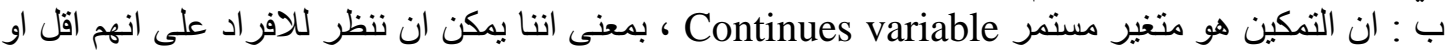

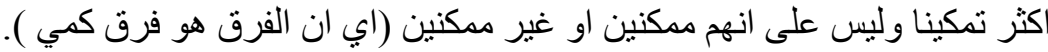

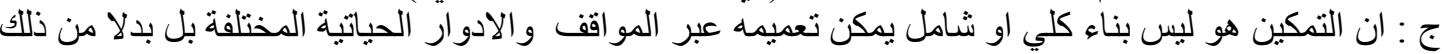

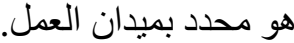
خامسا : ان ابز فرص تحقيق تمكين المراة هي التغيير في حركة المرأة والتفاعل الاجتماعي و التغيير في انماط

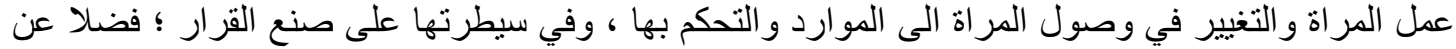

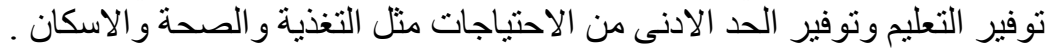

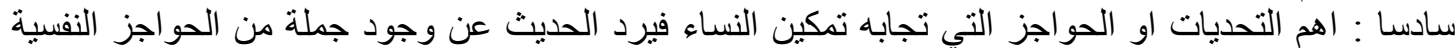

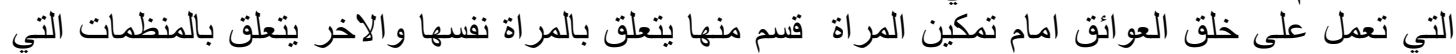

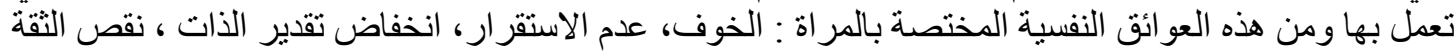

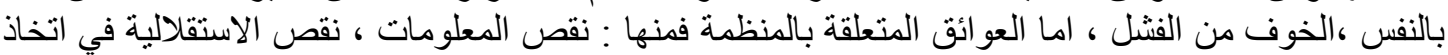

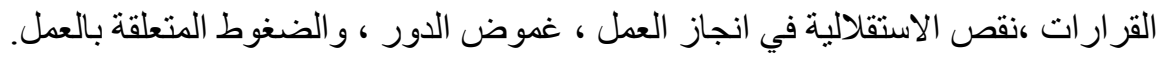
التوصيات :

في ضوء ماتم تقديمه في البحث الحالي يوصي البحث بامكانية الافـادة من المـادة النظريـة التي قدمت في البحث

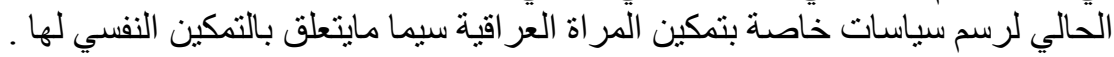

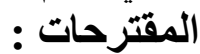

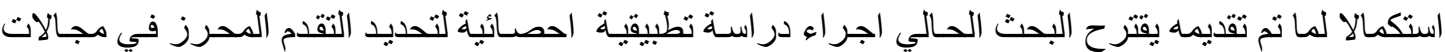
تمكين المر اة العر اقية وبحسب المجالات التي عرضت في البحث الحالي .

المصادر العربية

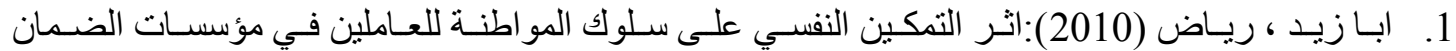

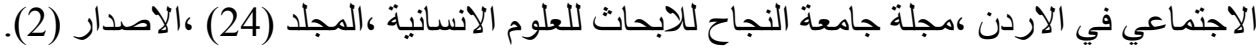

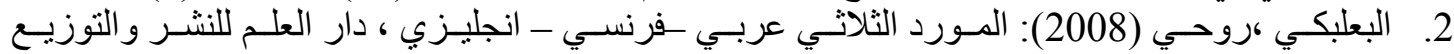

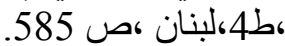




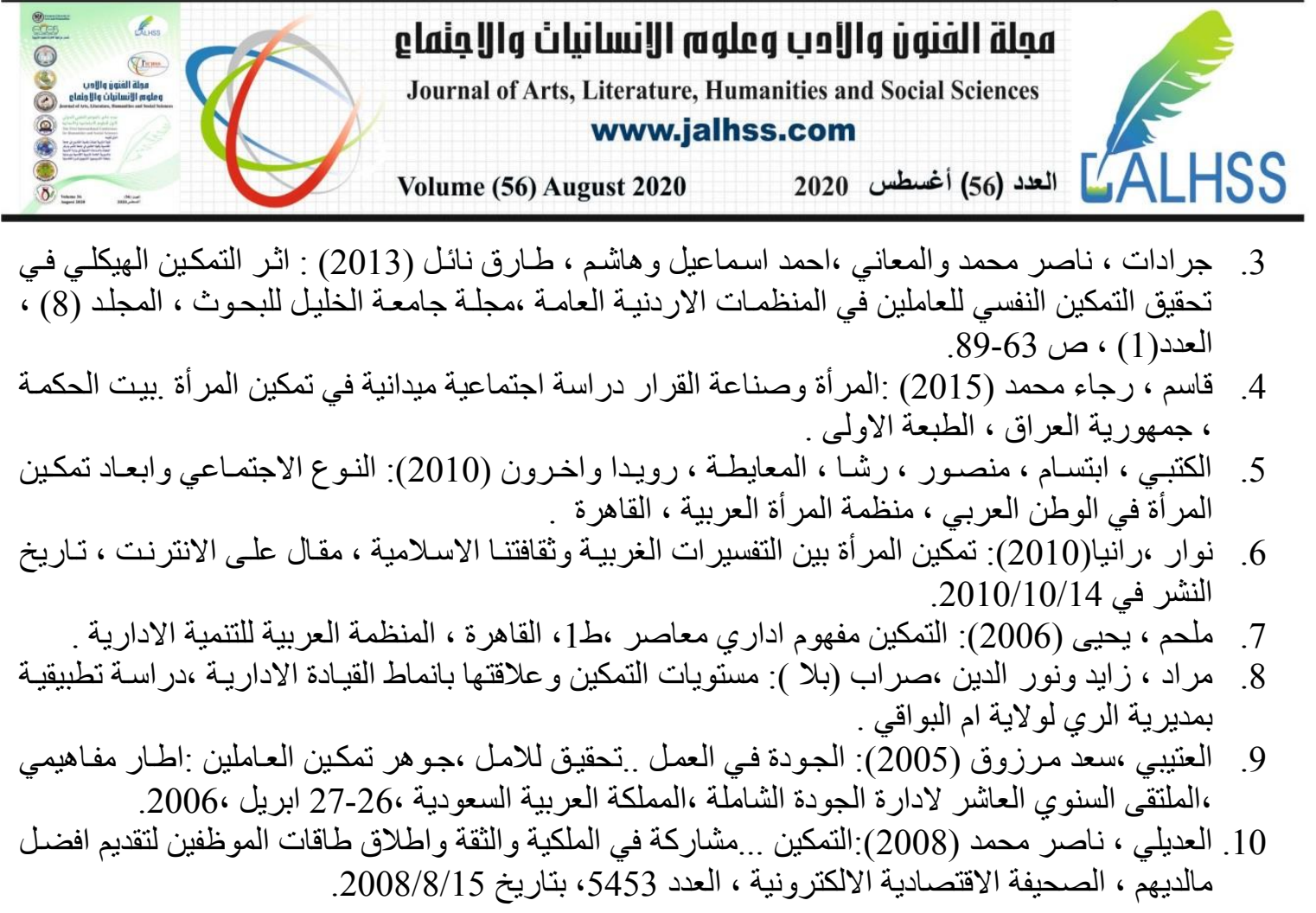

\section{References}

1. Aba Zaid, Riyadh (2010): The effect of psychological empowerment on citizenship behavior of workers in social security institutions in Jordan, An-Najah University Journal for Humanities Research, Volume (24), Issue (2).

2. Baalbaki, Rawhi (2008): The Trio Resource Arabic-French-English, Dar Al-Alam for Publishing and Distribution, 4th edition, Lebanon, p. 585.

3. Jaradat, Nasser Muhammad and Ma'ani, Ahmad Ismail and Hashem, Tariq Nael (2013): The effect of structural empowerment on achieving psychological empowerment for workers in public Jordanian organizations, Hebron University Journal for Research, volume (8), No. (1), pp. 63-89.

4. Qasim, Rajaa Muhammad (2015): Women and Decision Making: A Social and Field Study in Empowering Women. House of Wisdom, Republic of Iraq, First Edition.

5. Al-Ketbi, Ibtisam, Mansour, Rasha, Al-Maayta, Ruwaida and others (2010): Gender and Dimensions of Women's Empowerment in the Arab World, Arab Women Organization, Cairo.

6. Nawwar, Rania (2010): Empowering women between Western interpretations and our Islamic culture, online article, published on October 14, 2010.

7. Melhem, Yahya (2006): Empowerment A Contemporary Administrative Concept, 1st ed, Cairo, Arab Administrative Development Organization.

8. Murad, Zayed and Noordin, Sarab (none): levels of empowerment and their relationship to patterns of administrative leadership, an applied study in the Irrigation Directorate of the state of Umm Al-Baqi.

9. Al-Otaibi, Saad Marzouq (2005): Quality at Work ... Achieving Hope, the Essence of Empowering Workers: A Conceptual Framework, Tenth Annual Forum for Total Quality Management, Saudi Arabia, April 26-27, 2006. 


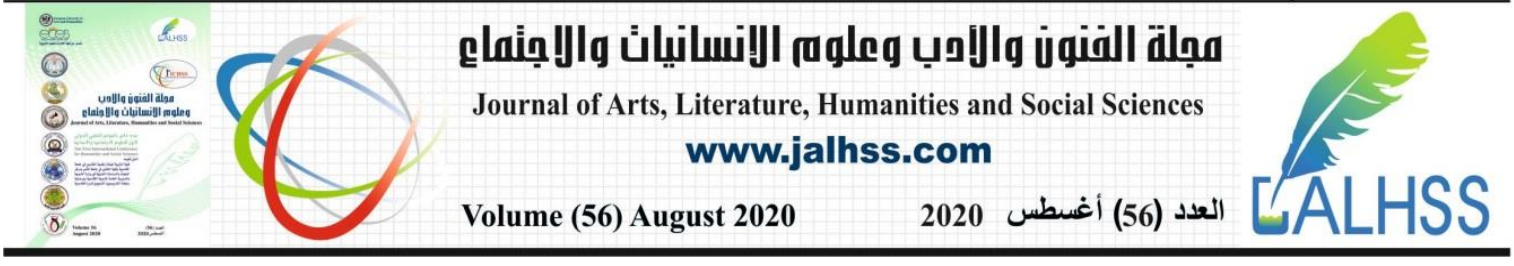

10. Al-Adili, Nasser Mohamed (2008): Empowerment ... Participation in ownership, trust and release of staff capabilities to present their best assets. The Economic Electronic Newspaper, Issue No. 5453, dated August 15, 2008.

11. -Aujvlat,Isabelle \&Horre,William\&Deccache,Alian (2006) : patient Empowerment in Theory and Practice .Patient Education and Counseling, vol(9), no.(8).

12. -Chandhry, Imran Sharif \& Nosheen, Farhana(2012): Women Empowerment in Pakistan w with Special Reference to Islamic Viewpoint: An Empirical Study. Pakistan Journal of Social Sciences (PJSS)Vol. 32, No. 1 (2012), pp.171-183.

13. Geleta, Esayas B. \& Idemudia E.\& Henry, Carol \& Nigatu B.(2017):The Challenges of Empowering Women: The Experience of Pulse novation Project in Southern Ethiopia.

14. Narayanan, Silvi(2017): Challenges of women empowerment in a private organization in Malaysia. International Journal for Studies on Children, Women, Elderly And Disabled, Vol. 1, (January)ISSN 0128-309X.

15. -Shettar, Rajeshwari M(2015): A Study on Issues and Challenges of Women Empowerment in India . IOSR Journal of Business and Management (IOSR-JBM)eISSN: 2278-487X, p-ISSN: 2319-7668. Volume 17, Issue 4.Ver. I (Apr.2015),PP1319 www.iosrjournals.org .

16. - Spritzers , Gretchen M. (1995): Psychological Empowerment in the Workplace: Dimensions, Measurement, and Validation. Academy of Management Journal, vol. 38 no. 5, pp.1442-1465.

17. -Thomas, K. W., \& Velthouse , B. A.(1990), Cognitive Elements of Empowerment, Academy of Management Review, 15: 666-681

18. Randolph and Sashkin (2002): Can Organizational Empowerment? Work in Multinational Settings, Academy of Management Executive, 16, vol. (1).

19. Mishra, Gunman (2016): The Psychological Facets of Women Empowerment at Workplace. International Journal of Recent Trends in Engineering Research, vol 2.Issue 11; November.

20. Varghese, Thresiamma (2011) :Women Empowerment in Oman: A study based on Women Empowerment Index . Far East Journal of Psychology and Business Vol. 2 No 2, February 201. 